\title{
Groei en productie van Amerikaanse eik in Nederland
}

J.J. Jansen ${ }^{1}$, A. Oosterbaan ${ }^{2}$, G.M.J. Mohren ${ }^{1}$ en J. den Ouden ${ }^{1}$

FEM Groei en Productie Rapport 2018-9

WAGENINGEN

UNIVERSITY \& RESEAREH

1 Forest Ecology and Forest Management group, Wageningen University, Department of Environmental Sciences

2 Nature and Society, Wageningen Environmental Research (WENR) 
Jansen, J.J., A. Oosterbaan, G.M.J. Mohren en J. den Ouden, 2018. Groei en productie van Amerikaanse eik in Nederland. FEM Groei en Productie Rapport 2018 - 9, 41 blz.

Synopsis: Van 1949 tot 1988 is in Nederland groei- en productieonderzoek bij de Amerikaanse eik uitgevoerd. Dat betreft de studies Wageningen Universiteit en van de Dorschkamp/IBN. Samen met de permanente steekproeven uit de HOSP zijn 58 proefperken met 306 opnamen beschikbaar. Voor de ontwikkeling van de opperhoogte $h_{\text {top }}$ met de leeftijd $t$ werd het heteromorfe model van Jansen \& Hildebrand gekozen, met asymptoot en 3 andere parameters. Als site index is voor de $h_{70}$ gekozen. De diameterontwikkeling tot een hoogte van $7 \mathrm{~m}$ is verklaard met een lineaire functie in $h_{\text {top }}$ en het beginstamtal $N_{0}$. Vanaf een opstand hoogte van $7 \mathrm{~m}$ is het model van jansen et al. (2016) gebruikt. Dat is een powerfunctie met $h_{\text {top }}, t$, opnamejaar yor en standruimte index van Hart ( $\left.S \%\right)$. Voor $S \%>$ 19.1 daalt de grondvlakbijgroei sterk met een niet-lineaire functie in $S \%$. Het model bevat een correctiefactor voor yor, deze bleek niet significant. Het effect van de dunning op de diameter na dunning is gemodelleerd met een gemodificeerd La Bastide-Faber model. Er zijn opbrengsttabellen gemaakt met één dunninggraad en vijf boniteiten.

Abstract: In the Netherlands growth and yield research on red oak was done from 1949 to 1988 . This includes studies by Becking and by the Dorschkamp/IBN research institute. Together with the permanent sample plots from the timber prognosis system HOSP, all this comprises a dataset of 58 plots with 306 recordings. For the development of top height $h_{\text {top }}$ with age $t$, Jansen \& Hildebrand's polymorphic model with site index $h_{70}$ and three additional parameters fitted best.

The diameter development up to stand height of $7 \mathrm{~m}$ was described with a linear function in $h_{\text {top }}$ and initial density $\left(N_{0}\right)$. From a stand height of $7 \mathrm{~m}$ and up, the basal area increment $\left(i_{G}\right)$ was described by Jansen's et al. model based on a power function with $h_{\text {top }}, t$, year of recording (yor), and the stand density index of Hart (S \%). For $S \%>19.1$ the basal area increment drops strongly non-linear with increasing $5 \%$. The model contains a correction factor for yor, which was not significant. The effect of thinning on the diameter after thinning, was modelled with a modified La Bastide-Faber model. The model was used to construct yield tables for with five site classes and one thinning intensity.

Keywords: Red oak, Quercus rubra, Netherlands, yield table, Becking-Hart spacing index, height growth models, basal area increment, La Bastide-Faber model for thinning effect.

Dit rapport is gratis te downloaden op: $\underline{\text { https://doi.org/10.18174/444098 }}$

Dit rapport is gebaseerd op de database: Oosterbaan, J.J. Jansen, J.F. Oldenburger, G.M.J. Mohren \& J. den Ouden, 2016. FEM growth and yield data Monocultures - red oak. DANS. http://dx.doi.org/10.17026/dans-z8d-wpah 


\section{Voorwoord}

In Nederland zijn er waarnemingen verricht in permanente proefperken van de Amerikaanse eik (Quercus rubra) tussen 1949 en 1988.

Jansen et al. (1996) kiezen in hun opbrengsttabellenboek voor de tabel van Faber (1996).

Bartelink et al. (2001) geven een uitgebreid overzicht van de context en publicaties van het groei- en productieonderzoek aan deze en andere boomsoorten in Nederland.

Samen met de permanente steekproefpunten van de HOSP is er de huidige studie de beschikking over de gegevens van 58 plots met 306 opnamen in het tijdvak 1949 tot 200.

In dit rapport wordt de ontwikkeling van opstanden van Amerikaanse eik met verschillende dunninggraden geanalyseerd met het doel een groeimodel te maken bij een ruim scala aan beheerstrategieën. Deze studie is de tiende in een serie, waarin de groei en productie van douglas (Jansen et al., 2016), Japanse lariks, fijnspar, grove den, zomereik, beuk, populier, Corsicaanse den en Oostenrijkse den werden bestudeerd.

De studie volgt waar mogelijk dezelfde werkwijze als de voorgaande studies en vaak zijn delen van de tekst uit deze rapporten (soms ook zonder bronvermelding) overgenomen. Maar met dit en volgende rapporten is er sprake van een vereenvoudigde werkwijze, omdat er beduidend minder gegevens ter beschikking zijn.

Om de toegankelijkheid voor niet Nederlandse lezer te verhogen zijn alle figuren, en formules en veel tabellen van Engelse tekst voorzien.

Hans Jansen,

Wageningen, 2018 


\section{Inhoud}

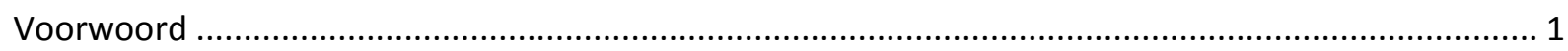

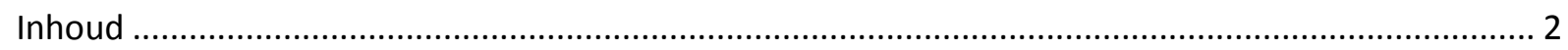

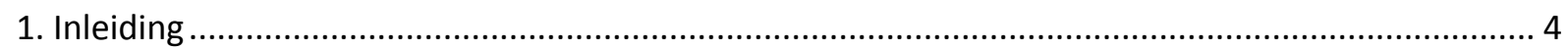

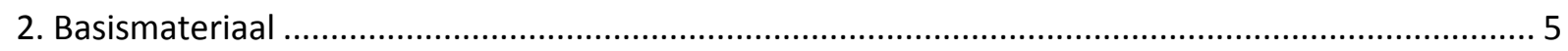

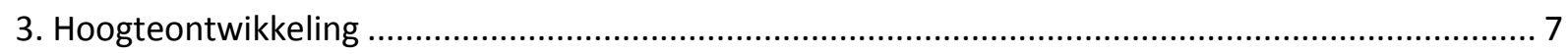

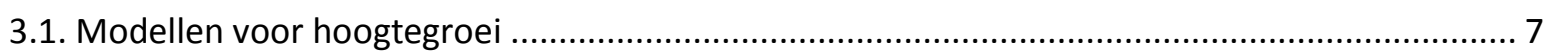

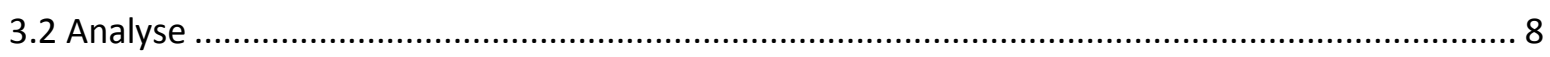



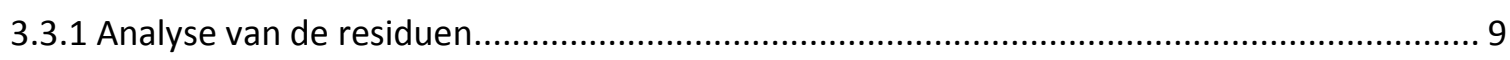

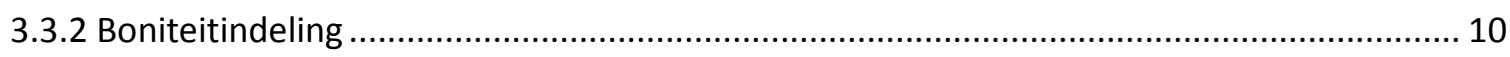

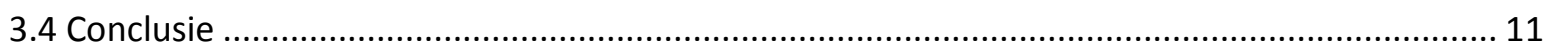







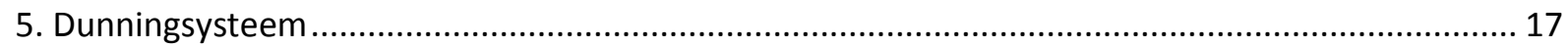

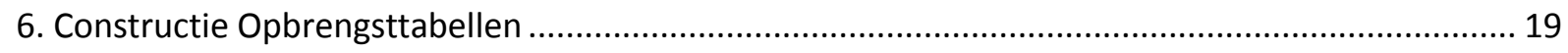

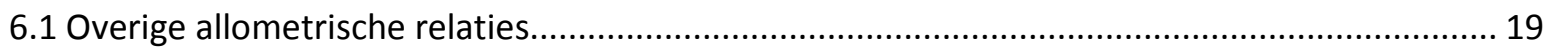

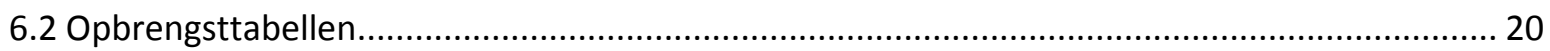

6.3 Vergelijking met andere opbrengsttabellen ............................................................... 22

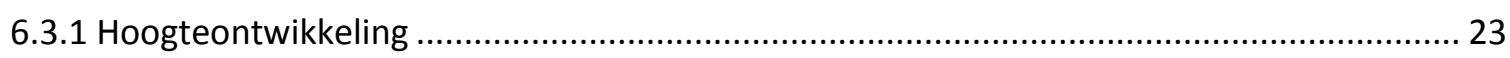

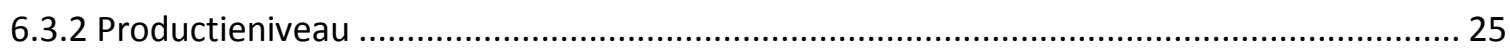

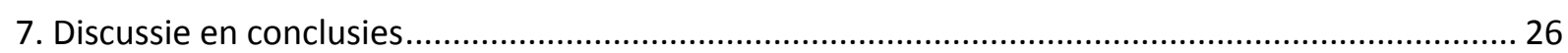



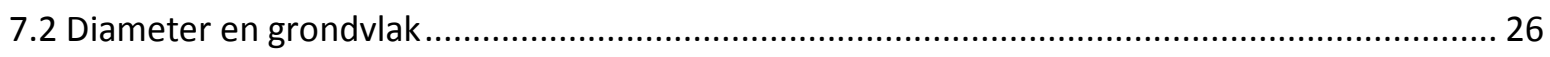

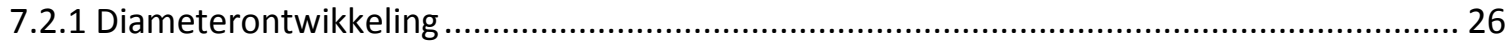



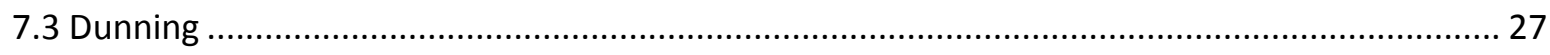

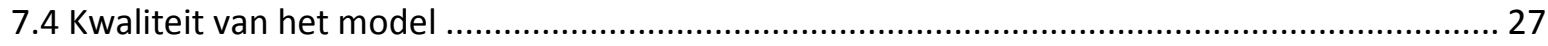

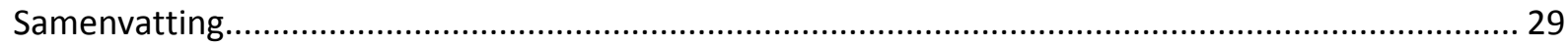

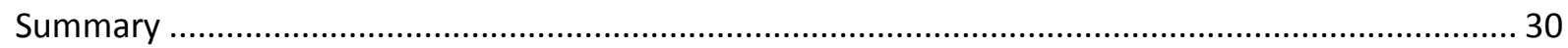

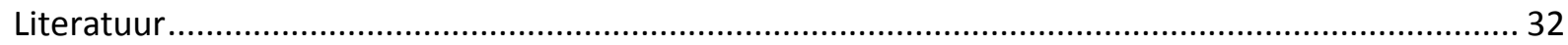

Bijlage 1. Opbrengsttabellen voor Amerikaanse eik Nederland 2018 .......................................... 34




Explanation yield tables



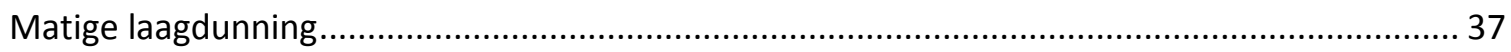




\section{Inleiding}

Tussen 1949 en 2000 zijn er gegevens verzameld over de groei van Amerikaanse eik. Met deze gegevens is het mogelijk modellen te maken die de ontwikkeling van Amerikaanse eikenopstanden bij een variatie aan beheerstrategieën verklaren en mogelijk voorspellen. Eén van de gebruikelijke modellen is een opbrengsttabel. Faber (1996) heeft een opbrengsttabel voor de Amerikaanse eik met één dunningregime gemaakt, welk geclassificeerd kan worden als een sterke tot zeer sterke laagdunning. Voor de tabel zelf zie Jansen et al. (1996). Een opbrengsttabel is een model waarmee de opstandontwikkeling in de tijd wordt beschreven en het bestaat meestal uit drie submodellen:

1. Model voor de hoogteontwikkeling, dit wordt In Hoofdstuk 3 besproken.

2. Model voor de grondvlakbijgroei in de tijd of relatief ten opzichte van de hoogte, waarmee het productieniveau van opstanden kan worden voorspeld, dit wordt In Hoofdstuk 4 besproken.

3. Model voor de dunning. Dit model moet een definitie geven van de dunninggraden, daarnaast is het de vraag wat de interactie is met model ad 2 bij verschillende dunninggraden. In Hoofdstuk 5 komen deze vragen aan de orde.

In hoofdstuk 2 worden de basisgegevens besproken. In Hoofdstuk 6 worden de 3 submodellen geïntegreerd tot een serie opbrengsttabellen. Deze worden vergeleken met andere tabellen. De opbrengsttabellen zijn te vinden in Bijlage 1. 


\section{Basismateriaal}

Sinds 1949 is er in Nederland onderzoek gedaan naar de ontwikkeling van Amerikaanse eikenopstanden in de studies 1 en 2 en daarnaast is het Nederlandse bos gemonitord in permanente steekproefpunten van studie 4 :

1. Dunningonderzoek Becking 1950-1981 met 2 proefperken met in totaal 16 opnamen. De behandeling betreft een laagdunning met een vaste dunninggraad;

2. Groei- en productieonderzoek Dorschkamp/IBN 1949-1988 ten behoeve van opbrengsttabellen. Er zijn 35 proefperken met 220 opnamen;

4. HOSP 1984-2000, in beheer bij Probos. Dit zijn ca. 3000 steekproefpunten uit de 4e bosstatistiek, die later gevolgd zijn in HOSP. Hieruit zijn 21 monocultures met Amerikaanse eik geselecteerd met in totaal 78 opnamen.

In totaal gaat het om 306 opnamen in 58 proefperken.

De proefvelden van studie 1 en 2 betreffen proefvakken met een vaste oppervlakte. Soms wordt die oppervlakte kleiner door stormschade. De gegevens zijn daarna opnieuw berekend over de kleinste oppervlakte. In studie 4 gaat het om vaste steekproefpunten met een variërende straal zodanig dat er minimaal 25 bomen in de steekproef liggen. Door kap of ingroei kan deze wijzigen. Alleen dat deel wat in alle opnamen aanwezig was is bij het onderzoek betrokken.

Voor het bepalen van de dunninggraad is het S-procent van Hart (1928) (ook bekend als de Hart-Becking Spacing Index) van alle perken en opnamen berekend met formule (1):

$$
S \%=\frac{a_{a t}}{h_{\text {top }}} \cdot 100=\frac{100}{h_{\text {top }}} \cdot \sqrt{\frac{10000}{N_{a t}} \cdot \frac{2}{\sqrt{3}}} \approx \frac{10745.7}{h_{\text {top }} \cdot \sqrt{N_{a t}}}
$$

In deze definitie is de gemiddelde boomafstand na dunning $\left(a_{a t}\right)$ bepaald met een regelmatig driehoekverband. Het symbool $h_{\text {top }}$ staat voor de opperhoogte.

Van alle proefperken zijn basisgegevens als oppervlakte, kiemjaar en ligging bekend.

De afzonderlijke metingen en berekeningen aan de bomen in de proefperken vormen de basisgegevens. Deze zijn daarna geaggregeerd tot kenmerken per ha per proefperk van voor, na, en van de dunning. De boomgegevens spelen in deze studie alleen een rol om de opstandkenmerken te genereren.

Per proefperk en opname zijn de gegevens beschikbaar, zoals vermeld in Tabel 1.

Voor een volledige beschrijving van gemeten en berekende gegevens zie de file "Read me FEM growth and yield data Monocultures - red oak.pdf" in de database FEM growth and yield data Monocultures - red oak (Oosterbaan et al., 2016). 
Tabel 1. Basisgegevens per plot en opname.

Table 1. Base information per plot and recording

\begin{tabular}{|l|l|l|}
\hline Naam & Symbool & Betekenis \\
\hline plotnr & & Plotnummer \\
region & & Studienummer \\
area & & Regio \\
yog & & Plotoppervlakte in ha \\
NO & $N_{0}$ & Kiemjaar \\
sperc & Beginstamtal \\
sperc0 & $S_{0} \%$ & gemiddelde Hart-Becking Spacing Index in plot \\
nrec & & Actuele Hart-Becking Spacing Index in de opname \\
rec & & Aantal opnamen \\
DOR & & Opname nummer \\
age & $t$ & Datum van de opname \\
htop & $h_{\text {top }}$ & Leeftijd in jr \\
hdom & $h_{d o m}$ & Opperhoogte in $\mathrm{m}$ \\
ddom & $d_{d o m}$ & Dominante hoogte in $\mathrm{m}$ \\
N_bt & $N_{b t}$ & Diameter van de dominante hoogte boom in cm \\
G_bt & $G_{b t}$ & Stamtal per ha voor dunning \\
h_bt & $h_{b t}$ & Grondvlak voor dunning in $\mathrm{m}^{2} /$ ha \\
dg_bt & $d_{b t}$ & Hoogte van de grondvlak-middenstam in $\mathrm{m}$ voor dunning \\
V_bt & $V_{b t}$ & Diameter van de grondvlak-middenstam in $\mathrm{cm}$ voor dunning \\
N_th & $N_{t h}$ & Volume voor dunning in $\mathrm{m}^{3} /$ ha \\
G_th & $G_{t h}$ & Stamtal per ha van de dunning \\
h_th & $h_{t h}$ & Grondvlak van de dunning in $\mathrm{m}^{2} /$ ha \\
dg_th & $d_{t h}$ & Hoogte van de grondvlak-middenstam in $\mathrm{m}$ van de dunning \\
V_th & $V_{t h}$ & Diameter van de grondvlak-middenstam in cm van de dunning \\
N_at & $N_{a t}$ & Volume van de dunning in $\mathrm{m}^{3} /$ ha \\
G_at & $G_{a t}$ & Stamtal per ha na dunning \\
h_at & $h_{a t}$ & Grondvlak na dunning in $\mathrm{m}^{2} /$ ha \\
dg_at & Hoogte van de grondvlak-middenstam in $\mathrm{m}$ na dunning \\
V_at & $d_{a t}$ & Diameter van de grondvlak-middenstam in cm na dunning \\
& & Volume na dunning in $\mathrm{m}^{3} / \mathrm{ha}$ \\
\hline
\end{tabular}




\section{Hoogteontwikkeling}

In deze studie zijn de HOSP plots ook voor de analyse gebruikt. In totaal zijn daardoor alle 58 plots met 306 opnamen gebruikt.

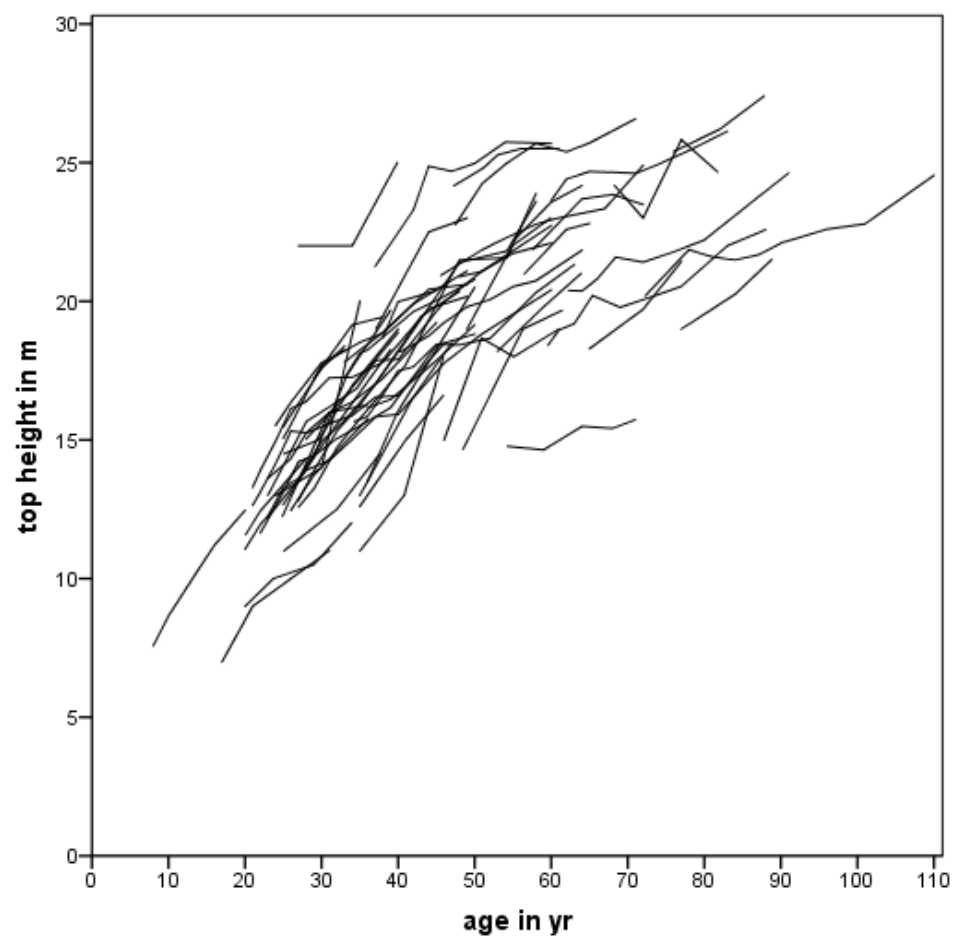

Figuur 1. Hoogteontwikkeling in de Amerikaanse eikenproefperken in Nederland.

Figure 1. Development of tree height in red oak plots in the Netherlands.

\subsection{Modellen voor hoogtegroei}

In de opbrengsttabellen tot ongeveer 1970 is de hoogteontwikkeling meestal handmatig gefit. Vanaf 1970 worden over het algemeen niet-lineaire groeifuncties gebruikt om de hoogteontwikkeling te fitten. In de huidige Nederlandse opbrengsttabel voor de Amerikaanse eik (Faber, 1996) is het Chapman-Richards model gebruikt:

$$
h_{\text {top }}=S \cdot\left(1-e^{-a \cdot t}\right)^{b}
$$

In Formule (2) is S de zogenaamde "site index" de proefperkspecifieke constante en de asymptoot in het model. Deze $S$ kan gezien worden als de afplattingshoogte en het is tevens een maat voor de boniteit, in dit geval een absolute hoogteboniteit. Daarnaast wordt ook de hoogte bij een vaste leeftijd als maat voor de boniteit gebruikt. Voor de Amerikaanse eik zal de $h_{70}$ worden gebruikt

De te onderzoeken modellen zijn Chapman-Richards, Burkhart \& Tennent, Jansen \& Hildebrand en Cieszewski, zie Paragraaf 3.2 voor formules en referenties. 


\subsection{Analyse}

De volgende vier modellen zijn onderzocht.

1. Het homomorfe model van Chapman-Richards (zie Pienaar \& Turnbull, 1973):

$$
h_{\text {top }}=S \cdot\left(1-e^{-a \cdot t}\right)^{b}
$$

2. Burkhart \& Tennent (1977) paste het Chapman-Richard model aan door de parameter $a$ als functie van $S$ uit te drukken waardoor een heteromorf model ontstaat:

$$
h_{\text {top }}=S \cdot\left(1-e^{-\left(a_{0}+a_{1} \cdot S\right) \cdot t}\right)^{b}
$$

3. Jansen \& Hildebrand (1986) pasten de werkwijze van Burkhart \& Tennent toe op de $b$-parameter, hierdoor ontstaat eveneens een heteromorf model:

$$
h_{\text {top }}=S \cdot\left(1-e^{-\alpha \cdot t}\right)^{\left(b_{0}-b_{1} \cdot S\right)}
$$

Jansen et al. (2016) pasten model (5) aan door een jeugdgroei-component toe te voegen. Maar omdat data betreffende de jeugdgroei nagenoeg ontbreken (zie Figuur 1 ) is dit model niet onderzocht.

4. Het Cieszewski model (2001) gebruikt een referentieleeftijd, voor $t=70$ jaar luidt het:

$$
h_{\text {top }}=h_{70} \cdot \frac{t^{a} \cdot\left(70^{a} \cdot R+b\right)}{70^{a} \cdot\left(t^{a} \cdot R+b\right)}, \text { where } R=Z+\sqrt{Z^{2}+\frac{2 \cdot b \cdot h_{70}}{70^{a}}} \text { and } Z=h_{70}-c
$$

Dit heteromorfe model heeft wel een asymptoot, maar de oplossing moet gevonden worden met formule (6).

Het model van Jansen \& Hildebrand (1986) verklaarde verreweg het meest van de variantie en is daarom gekozen.

\subsection{Uiteindelijke model}

In formule (7) en alle volgende vergelijkingen die een onderdeel van het opbrengstmodel vormen worden de parameters genummerd als $c_{1}, c_{2}$ enzovoorts.

$$
\begin{aligned}
h_{\text {top }}= & S \cdot\left(1-e^{-c_{1} \cdot t}\right)^{b} \\
& \text { where } b=c_{2}-c_{3} \cdot S
\end{aligned}
$$

Met een $R^{2}$ adj van 0.970 werd de parameterschatting van Tabel 2 gevonden 
Tabel 2. Parameterschatting van model (7).

Table 2. Parameters for model (7).

\begin{tabular}{|l|c|c|r|r|}
\hline \multirow{2}{*}{ Parameter } & & & \multicolumn{2}{|c|}{ 95\% Confidence Interval } \\
\cline { 4 - 5 } & Estimate & Std. Error & Lower Bound & \multicolumn{1}{c|}{ Upper Bound } \\
\hline$c_{1}$ & 0.0199 & 0.003 & 0.014 & 0.025 \\
$c_{2}$ & 5.2936 & 2.223 & 0.915 & 9.672 \\
$c_{3}$ & 0.1462 & 0.074 & 0.000 & 0.293 \\
\hline
\end{tabular}

In Figuur 2 is de met Formule (7) voorspelde opperhoogte uitgezet tegen de gemeten opperhoogte. De gearceerde rode lijn betreft de lineaire fit, deze ligt nagenoeg geheel op de perfecte fit lijn met een hoek onder $45^{\circ}$.

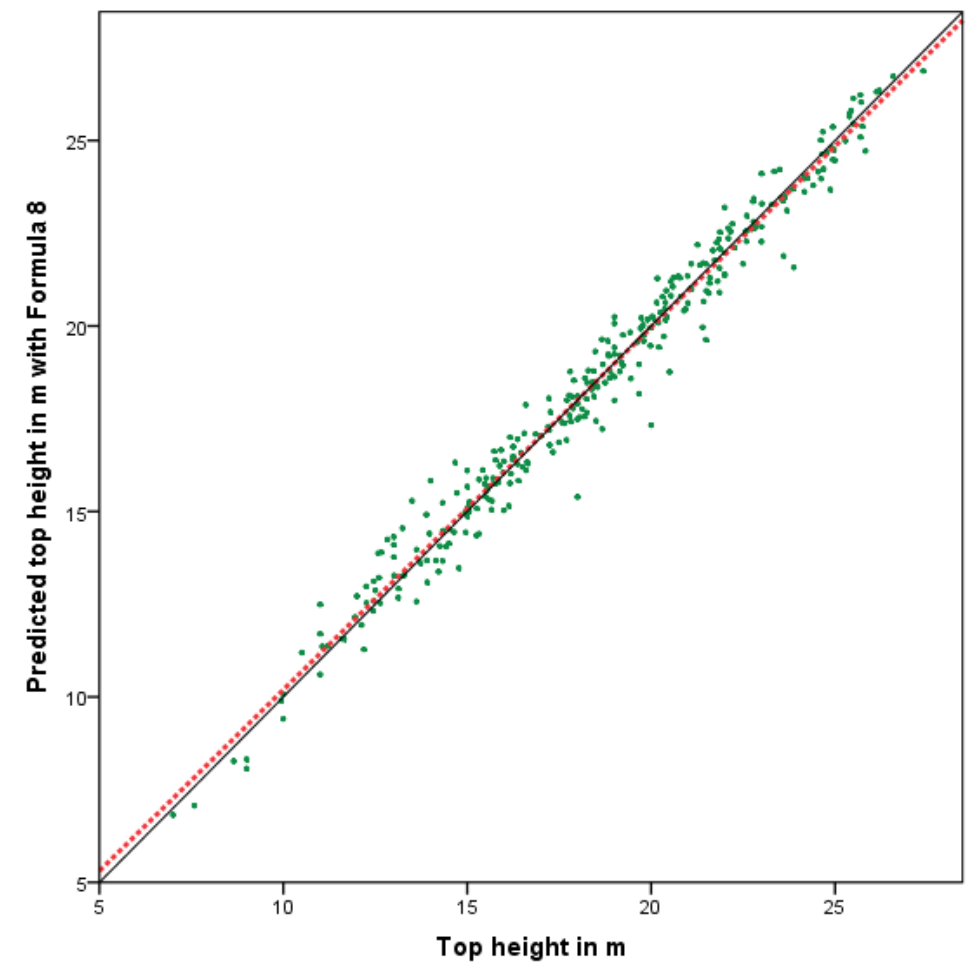

Figuur 2. Voorspelde opperhoogte met Formule (7) in relatie met gemeten opperhoogte op tijdstip van de waarneming. De rode lijn geeft lineaire fit weer, de zwarte lijn geeft de perfecte fit met een hoek van $45^{\circ}$ weer.

Figure 2. $\quad$ Predicted top height with model (7) in relation with observed top height at recording time. The red line represents the linear fit, the black line the perfect fit with an angle of $45^{\circ}$.

\subsubsection{Analyse van de residuen}

Bij lineaire regressie is het gebruikelijk naar uitbijters te kijken om fouten op te sporen. De residuen van de NLR met Formule (7) zijn uitgezet tegen de systeemvariabele leeftijd en de afgeleide systeemvariabele $h_{70}$ (Figuur 3 ). 

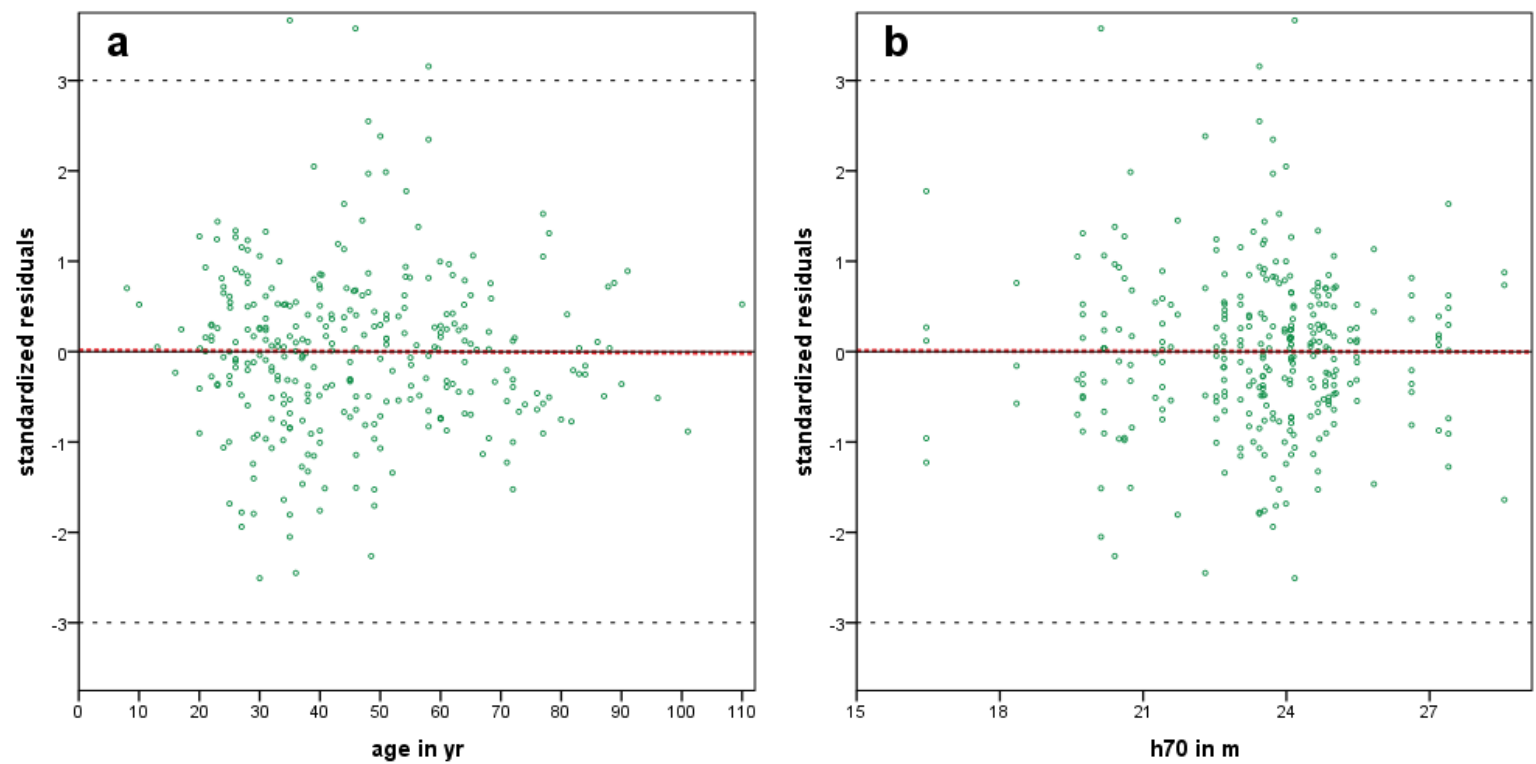

Figuur 3. Gestandaardiseerde residuen in relatie tot leeftijd (a) en $h_{70}(b)$, de rode lijn geeft de lineaire fit weer.

Figure 3. Standardized residuals in relation to top height (a) and $h_{70}(b)$, the red line is the linear fit.

In Figuur 3 is te zien dat er geen onzuiverheid is in het model ten opzichte van beide modelvariabelen en er zijn drie uitbijters aanwezig, die niet verklaard konden worden.

\subsubsection{Boniteitindeling}

Met de gegevens van de $4^{\mathrm{e}}$ bosstatistiek (CBS, 1985) is van 3027 monocultures met Amerikaanse eik de $h_{70}$ bepaald volgens de methode van Jansen et al. (2016). Dit leidt tot de verdeling over de $h_{70}$ zoals weergegeven in Figuur 4.

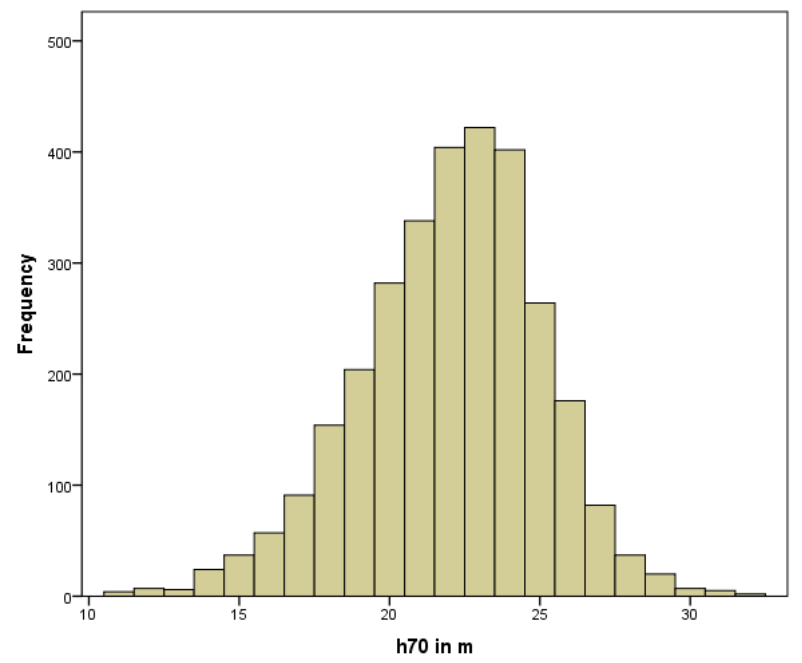

Figuur 4. Frequentiehistogrammen van $h_{70}$ in $4 e$ bosstatistiek.

Figure 4. Frequency histograms of $h_{70}$ in the Fourth Dutch Forest Inventory.

De grenzen voor een boniteitindeling zijn zo gekozen dat 95 tot $99 \%$ van de opstanden in de klassen I tot en met $\mathrm{V}$ valt. Zie Tabel 3 voor het resultaat. Met deze indeling heeft $0.8 \%$ van 
alle opstanden van de Amerikaanse eik een betere boniteit dan de $\mathrm{I}^{\mathrm{e}}$ en $0.9 \%$ heeft een slechtere boniteit dan de $\mathrm{V}^{\mathrm{e}}$.

Tabel 3. Indeling in boniteiten gebaseerd op de $\boldsymbol{h}_{70}$.

Table 3. Classification in site classes based on the $h_{70}$.

\begin{tabular}{|c|c|c|r|r|}
\hline $\begin{array}{c}\text { Boniteit } \\
\text { site class }\end{array}$ & $\begin{array}{c}\boldsymbol{h}_{\mathbf{7 0}} \\
h_{70}\end{array}$ & $\begin{array}{c}\text { Bereik } \boldsymbol{h}_{\mathbf{7 0}} \\
\text { range } h_{70}\end{array}$ & $\begin{array}{r}\text { \% in data set } \\
\text { \% in data set }\end{array}$ & $\begin{array}{r}\text { \% in } \mathbf{4}^{\mathrm{e}} \text { Bosstatistiek } \\
\text { \% in 4th forest inventory }\end{array}$ \\
\hline$<$ I & & $>28.8$ & & 0.8 \\
I & 27.3 & $(25.8-28.8)$ & 8.5 & 7.6 \\
II & 24.3 & $(22.8-25.8)$ & 59.5 & 34.5 \\
III & 21.3 & $(19.8-22.8)$ & 25.5 & 35.7 \\
IV & 18.3 & $(16.8-19.8)$ & 4.9 & 16.4 \\
V & 15.3 & $(13.8-16.8)$ & 1.6 & 4.2 \\
$>$ V & & $<13.8$ & & 0.9 \\
\hline
\end{tabular}

In Figuur 5 is de hoogteontwikkeling per boniteit samen met die van de proefperken en met die van de gegevens van de $4^{\mathrm{e}}$ Bosstatistiek weergegeven. Het is overduidelijk dat de jeugdontwikkeling van de beste boniteiten te steil verloopt. Maar een verbetering op basis van de data werd niet gevonden.
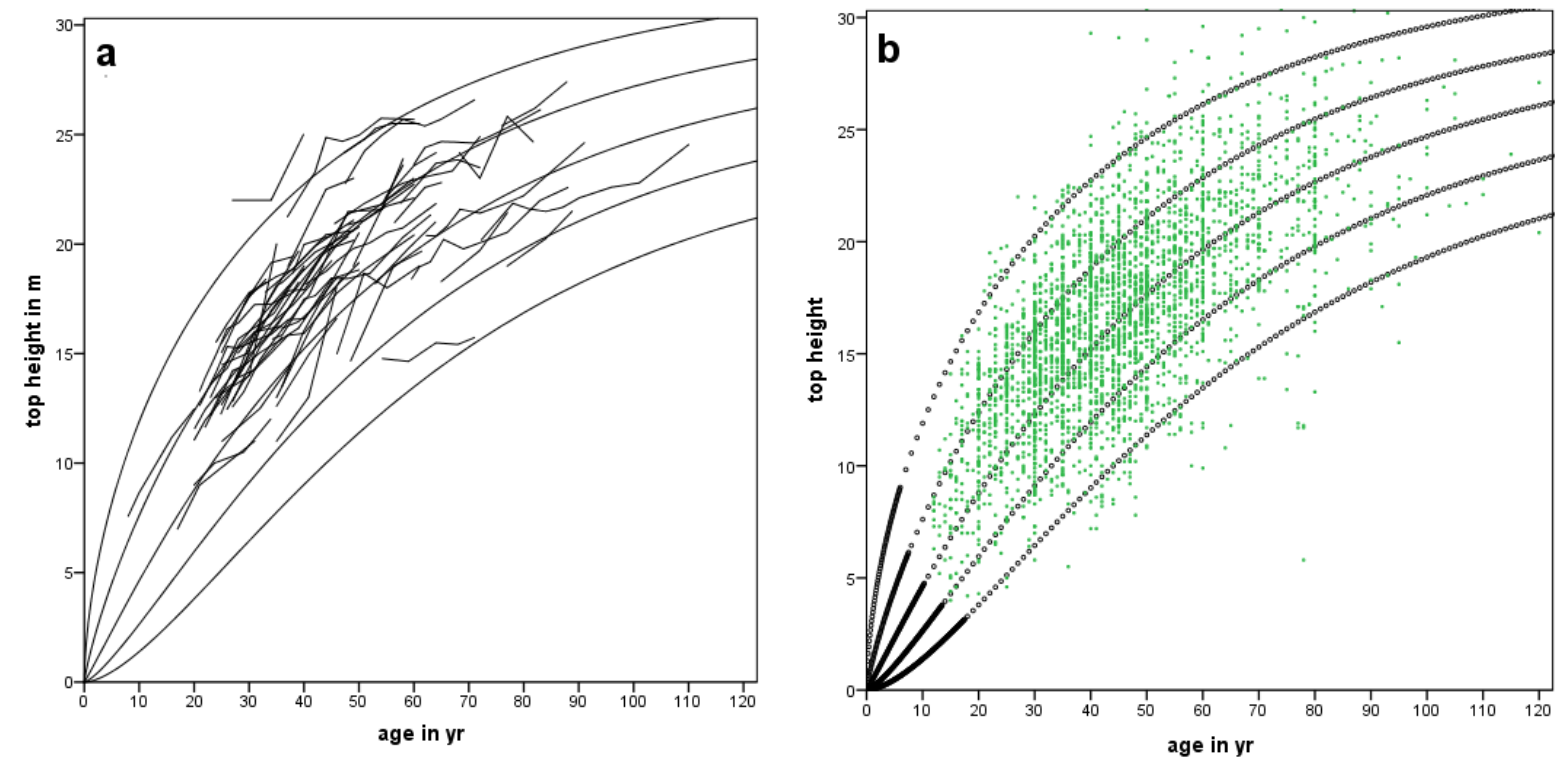

Figuur 5. Boniteitcurven voor de Amerikaanse eik in Nederland met de hoogteontwikkeling van de proefperken(a) en met de waarnemingen van de $4^{e}$ Bosstatistiek (b).

Figure 5. Site curves for red oak in the Netherlands with top height development of the experimental plots (a) and with data of Fourth National Forest inventory (b).

\subsection{Conclusie}

De hoogtegroei van de Amerikaanse eik is onderzocht en het model van Jansen \& Hildebrand is gekozen. Hiermee is een indeling in 5 boniteiten gemaakt. Ongeveer $1 \%$ van de Amerikaanse eikenbossen in Nederland heeft een betere boniteit dan de hier gepresenteerde boniteit I, en eveneens $1 \%$ heeft een lagere boniteit dan boniteit $\mathrm{V}$. 


\section{Opbrengstniveau}

Naast de hoogtegroei vindt ook diktegroei plaats. Dit resulteert in diameterbijgroei $i_{d}=\left(d_{2}-d_{1}\right) /\left(t_{2}-t_{1}\right)$ en grondvlakbijgroei $i_{G}=\left(G_{2}-G_{1}\right) /\left(t_{2}-t_{1}\right)$. Hoogtegroei en diktegroei samen resulteren in een volumebijgroei. In opbrengsttabellen is een belangrijk doel juist de volumebijgroei te bepalen. Aangezien het boomvolume in de dataset een afgeleide, berekende variabele is en niet berust op een primaire waarneming, zal ook de volumebijgroei indirect worden berekend. Diameter en het totale grondvlak zullen in de loop van de tijd toenemen, maar gelijktijdig neemt ook de hoogte toe.

Jansen et al. (2016) onderzochten voor douglas een aantal groeimodellen. Ze vonden dat tot een opperhoogte van $7 \mathrm{~m}$ de opstandontwikkeling het best kan worden verklaard met een voorspelling van de diameter voor dunning. Vanaf een opperhoogte $7 \mathrm{~m}$ werd de opstandontwikkeling beter verklaard door de grondvlakbijgroei. In Paragraaf 4.1 zal de diameterontwikkeling en daaraan gekoppeld de grondvlakontwikkeling worden geanalyseerd en gemodelleerd. In Paragraaf 4.2 zal de grondvlakbijgroei vanaf een hoogte van $7 \mathrm{~m}$ worden geanalyseerd en gemodelleerd.

\subsection{Diameter- en grondvlakontwikkeling tot een hoogte van $7 \mathrm{~m}$}

Als maat voor de diameter is gekozen voor de "gemiddelde" diameter van de opstand voor dunning $\left(d_{b t}\right)$. Onder "gemiddelde" wordt hier verstaan het kwadratische gemiddelde. Het gaat dus om de $d_{g}$, maar de toevoeging $g$ (van gemiddeld grondvlak) is weggelaten. Jansen et al. (2016) gebruikten voor de diameterontwikkeling van Douglas tot een hoogte van $7 \mathrm{~m}$ een model waarbij het beginstamtal $N_{0}$ een cruciale rol speelt, dit gegeven is alleen bekend voor studie 1 ( 2 van de 37 plots) en is daarom niet bruikbaar. Er moet daarom een ander model worden ontwikkeld. Daartoe zijn alle opnamen geselecteerd tot 35 jaar.
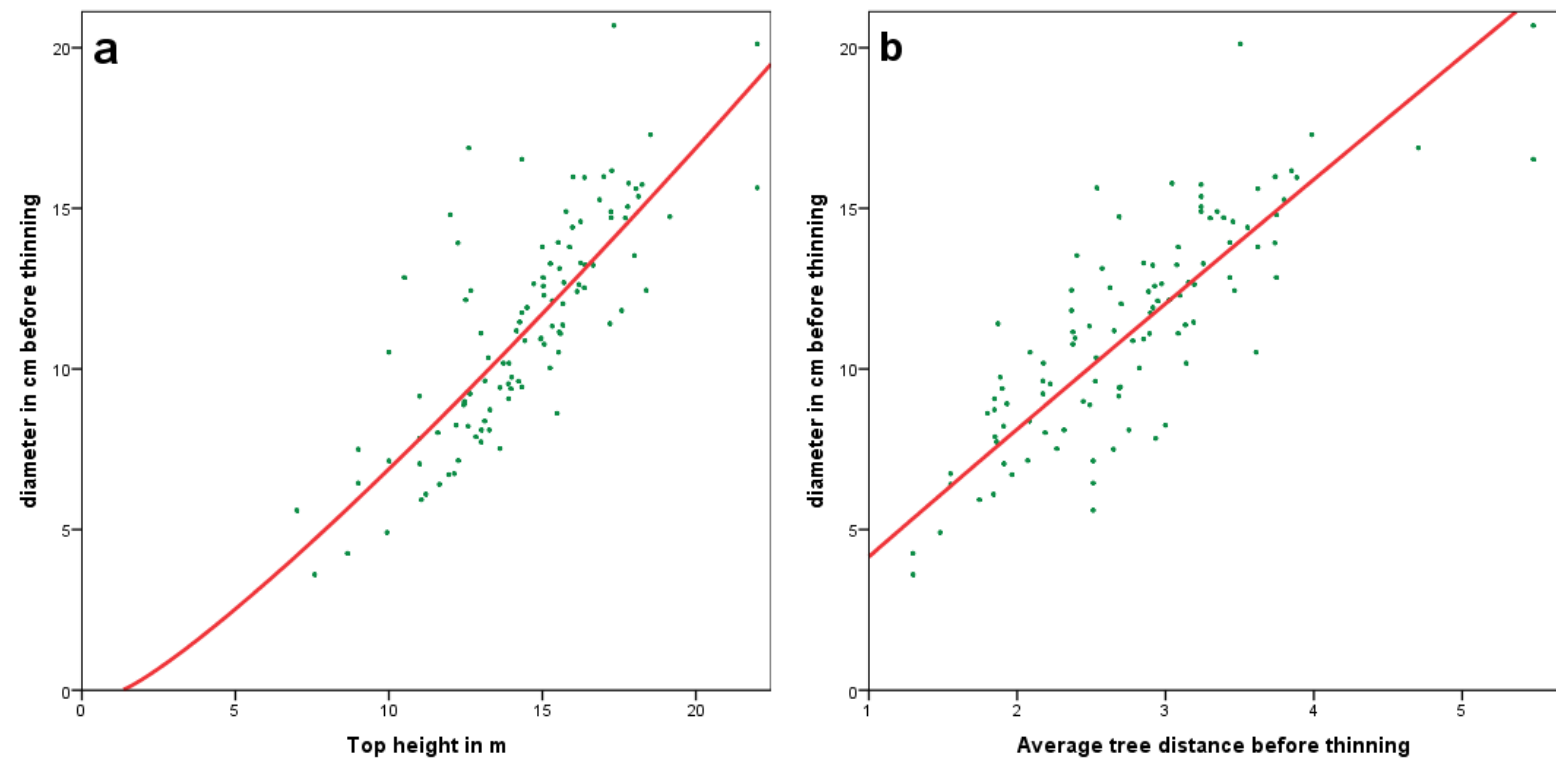

Figuur 6. Verloop diameterontwikkeling als functie van opperhoogte(a) en als functie van de gemiddelde boomafstand (b) met in rood de beste fit met een powerfunctie.

Figure 6. Course of the diameter development as a function of top height (a) and as a function of the average tree distance (b). The red lines represent the best fit with a power function. 
Er zijn geen data met een hoogte beneden de $7 \mathrm{~m}$ beschikbaar. In Figuur 6a zijn de paren $\left(d_{a t}, h_{t o p}\right)$ uitgezet en in Figuur $6 \mathrm{~b}$ de paren $\left(d_{a t}, a_{a t}\right)$ met in beide figuren de best fittende powerfunctie.

Hiermee is het volgende model ontwikkeld:

$$
d_{b t}=c_{5}+c_{6} \cdot h_{t o p}^{1.5}+c_{7} \cdot a_{b t} \quad \text { where } a_{b t}=\text { the average tree distance in } \mathrm{m}
$$

Model (8) werd opgelost met een $R^{2}$ adj van 0.934 , een standaard afwijking van $0.78 \mathrm{~cm}$ en de parameters van Tabel 4.

Voor de ontwikkeling tot een hoogte van $7 \mathrm{~m}$ en $N_{0}=5000$ met gebruikmaking van de powervariant van het model van Jansen et al. (2016) en Formule (8) om $d_{7}$ te bepalen geldt dan:

$$
d_{b t}=d_{7} \cdot\left(\frac{h_{\text {top }}-1.30}{7-1.30}\right)^{c_{4}} \text { for } h_{\text {top }} \leq 7 \mathrm{~m} \quad \text { where } d_{7}=c_{5}+c_{6} \cdot 7^{1.5}+c_{7} \cdot \frac{107.457}{\sqrt{5000}}
$$

Model (9) is bij gebrek aan waarnemingen niet oplosbaar, voor de parameter $c_{4}$ is de waarde 1 (lineaire groei gekozen). $D_{7}$ bedraagt $3.5 \mathrm{~cm}$ voor $N_{0}=5000$.

Tabel 4. Parameters voor Model (8) en (9).

Table 4. Parameters for Model (8) en (9).

\begin{tabular}{|l|r|r|r|r|}
\hline \multirow{2}{*}{ Parameter } & \multicolumn{2}{|c|}{ Estimate } & Std. Error & \multicolumn{2}{|c|}{ 95\% Confidence Interval } \\
\cline { 4 - 5 }$c_{4}$ & 1 & & & Upound \\
$c_{5}$ & -2.7905 & 0.383 & -3.550 & -2.031 \\
$c_{6}$ & 0.1216 & 0.006 & 0.110 & 0.134 \\
$c_{7}$ & 2.6567 & 0.122 & 2.415 & 2.898 \\
\hline
\end{tabular}

Figuur 7 laat zien dat er geen reden is om aan model (8) te twijfelen. 

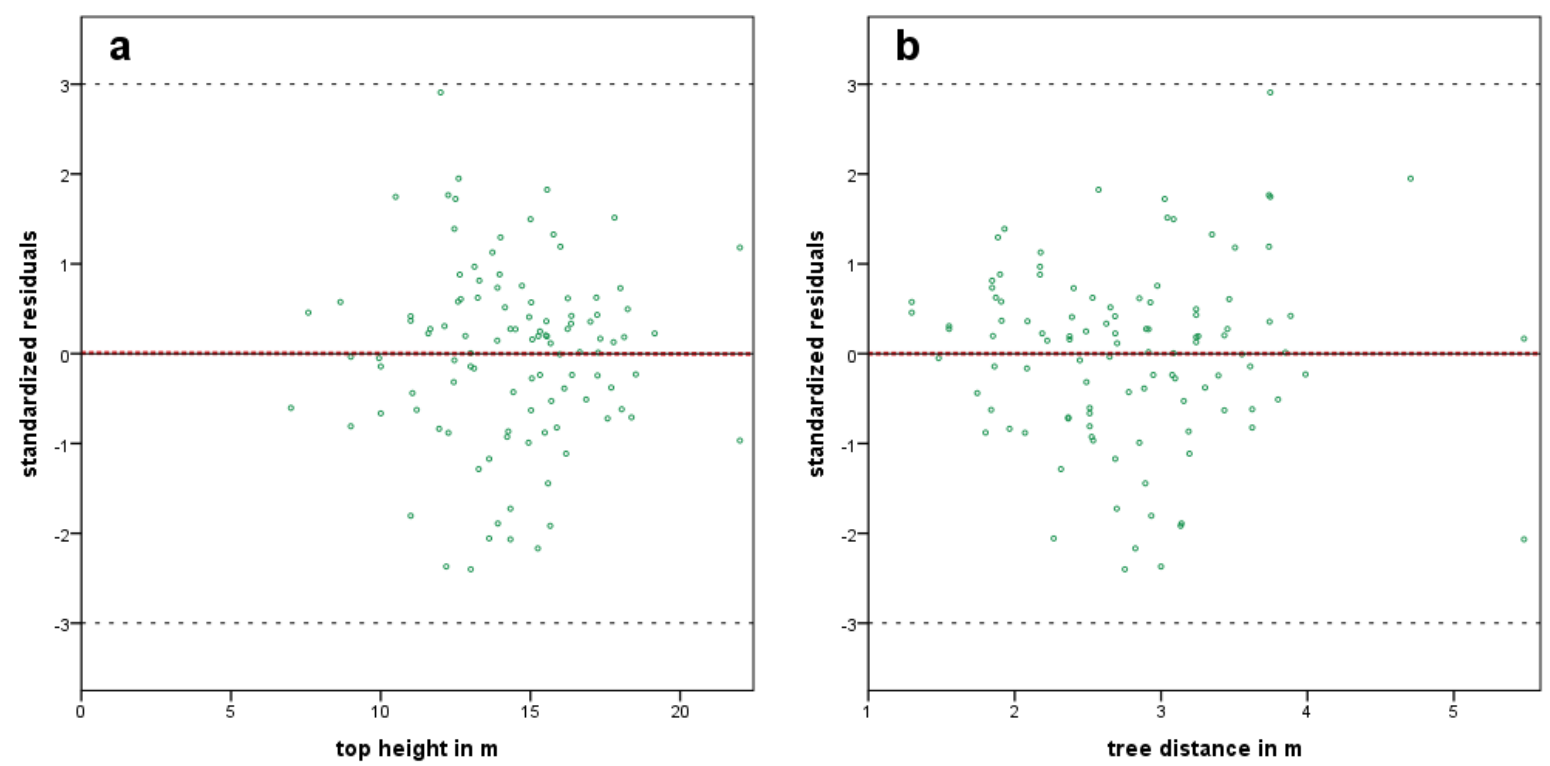

Figuur 7. Gestandaardiseerde residuen in relatie tot $h_{\text {top }}(a)$ en $a_{b t}(b)$, de rode lijn geeft de lineaire fit weer.

Figure 7. Standardized residuals in relation to age (a) and tree distance (b), the red lines represent linear fit.

\section{Conclusie}

Op een indirecte wijze is model (9) opgelost, de startwaarde voor $d_{7}$ kon bepaald worden, de weg erheen blijft een gok.

\subsection{Grondvlakbijgroei}

Bij de analyse van de grondvlakbijgroei is als grens is een opperhoogte van $7 \mathrm{~m}$ aangehouden, ontwikkeling van het grondvlak tot die hoogte is in Paragraaf 4.1 al besproken. Hier wordt de groei vanaf een opperhoogte van $7 \mathrm{~m}$ behandeld. 



Figuur 8. Grondvlakbijgroei als functie van de leeftijd (a) en opperhoogte (b). De zwarte lijnen geven het verloop binnen één plot aan, de rode lijn de beste fit voor een power-functie over alle opnamen.

Figure 8. The basal area increment as a function of age (a) and top height (b). The black line represents the course within one plot, the red line represents the best fit with a power function.

De grondvlakbijgroei betreft een berekende waarneming tussen 2 opnamen, de leeftijd en opperhoogte betreffen dan het gemiddelde tussen beide opnamen.

Totaal zijn er 241 opnamen beschikbaar voor de analyse

Jansen et al. (2016) ontwikkelden voor de grondvlakbijgroei van douglas het volgende model:

$$
i_{G, j k}=Y I_{j} \cdot P L_{k} \cdot f_{1}(S \%) \cdot f_{2}\left(h_{r e f}\right) \cdot\left\{\frac{F_{3}\left(h_{2}, t_{2}\right)-F_{3}\left(h_{1}, t_{1}\right)}{\Delta t}\right\}
$$

where $Y I=$ year index and $P L=$ plot level

Voor de douglas bleek $f_{2}$ geen significante bijdrage te leveren.

Hierin is $F_{3}$ een power-functie. In de Figuren $8 \mathrm{a}$ en $8 \mathrm{~b}$ zijn de afgeleiden van $F_{3}$ naar $t$ en $h_{\text {top }}$, in beide gevallen dus weer een powerfunctie, getekend. Op grond daarvan mag geconstateerd worden dat een powermodel zoals Jansen et al. (2016) gebruiken geschikt is om de grondvlakbijgroei te verklaren. Het uitgewerkte model zonder jaarindex $Y I$ of de correctiefactoren $c f_{80}$ voor de periode voor en na 1980 en zonder plotniveau luidt: 


$$
\begin{aligned}
& i_{G}=\operatorname{cor}_{5 \%} \cdot c_{8} \cdot\left\{c_{12} \cdot \operatorname{Term}_{h} / d t+\left(1-c_{12}\right) \cdot \operatorname{Term}_{t} / d t\right\} \\
& \text { where } \operatorname{Term}_{h}=\left(h_{2 c}-1.30\right)^{c_{11}}-\left(h_{1}-1.30\right)^{c_{11}} \\
& \operatorname{Term}_{t}=\left(t_{2}-t_{130}\right)^{c_{11}}-\left(t_{1}-t_{130}\right)^{c_{11}} \\
& t_{1}=t_{i, j} \text { and } t_{2}=t_{i, j+1} \text { for the } j^{\text {th }} \text { record in the } i^{\text {th }} \text { plot } \\
& h_{2 c}= \begin{cases}h_{2} & \text { for } h_{2}>h_{1} \\
h_{1}+\hat{h}_{2}-\hat{h}_{1} & \text { for } h_{2} \leq h_{1}\end{cases} \\
& h_{1} \text { and } h_{2} \text { are the top heights at time } t_{1} \text { and } t_{2} \\
& \operatorname{cor}_{S \%}= \begin{cases}1 & \text { for } S \%_{0} \leq c_{10} \\
1-c_{9} \cdot \sqrt{S \%_{0}-c_{10}} & \text { for } S \%_{0}>c_{10}\end{cases} \\
& S \%_{0}=\text { Hart-Becking spacing index after thinning at time } t_{1}
\end{aligned}
$$

Met $R^{2} \mathrm{adj}=0.458$ en standaarddeviatie $0.20 \mathrm{~m}^{2} \mathrm{jr}^{-1} \mathrm{ha}^{-1}$ werden de parameters van Tabel 5 gevonden. Voor de douglas bleek de toevoeging van de leeftijd geen extra verklaring te geven, voor de Amerikaanse eik is die wel van belang en $f_{2}$ speelt net als bij de douglas geen rol. In een daarna uitgevoerde regressiediagnose kwamen geen punten van nader onderzoek aan de orde.

Tabel 5. Parameterschatting met Model (11).

Table 5. Parameter estimation with Model (11).

\begin{tabular}{|l|rrrr|}
\hline & \multicolumn{3}{c}{ 95\% Confidence Interval } \\
Parameter & \multicolumn{1}{c}{ Estimate } & \multicolumn{1}{c|}{ Std. Error } & Lower Bound & Upper Bound \\
\hline$c_{8}$ & 4.0326 & 0.874 & 2.310 & 5.755 \\
$c_{9}$ & 0.0821 & 0.012 & 0.059 & 0.105 \\
$c_{10}$ & 19.1177 & 0.874 & 17.396 & 20.839 \\
$c_{11}$ & 0.7262 & 0.049 & 0.630 & 0.822 \\
$c_{12}$ & 0.2907 & 0.056 & 0.181 & 0.400 \\
\hline
\end{tabular}




\section{Dunningsysteem}

In de dunningproeven van studie 1 en 2 zijn verschillende vaste dunninggraden nagestreefd (zie Tabel 6).

Tabel 6. Dunninggraden

Table 6. Thinning grades

\begin{tabular}{|c|c|l|}
\hline Tgr & S\% bij $\mathbf{3 5} \mathbf{~ j r}$ & Omschrijving \\
\hline 1 & 13 & zonder dunning \\
2 & 16 & zwakke laagdunning \\
3 & 19 & matige laagdunning \\
4 & 22 & sterke laagdunning \\
5 & 25 & zeer sterke laagdunning \\
6 & 28 & open stand \\
\hline
\end{tabular}

Er is reden om aan te nemen dat de dunninggraad, zoals hier gedefinieerd via het $S \%$, op latere leeftijd moet stijgen omdat de vorm wijzigt zodra topsterfte optreedt.

Het model luidt dan:

$$
S \%= \begin{cases}13+3 \cdot\left(\operatorname{Tgr}_{0}-1\right) & \text { age } \leq 35 \\ 13+3 \cdot\left(\operatorname{Tgr}_{0}-1\right)+c_{13} \cdot(\text { age }-35) & \text { age }>35\end{cases}
$$

Vanaf de eerste dunning of sterfte tot een leeftijd van 35 jaar komt het $S \%$, behorend bij de in te stellen dunninggraad $\operatorname{Tg}_{0}$, overeen met die uit de tweede kolom van de tabel, daarna loopt het $S \%$ langzaam op.

Een model om $c_{13}$ te schatten luidt:

$$
S \%_{i j}=\left\{\begin{array}{ll}
S \%_{j} & \text { age } \leq 35 \text { and } h_{\text {top }}>7 \\
S \%_{j}+c_{13} \cdot\left(a g e_{i j}-35\right) & \text { age }>35 \text { and } h_{\text {top }}>7
\end{array} \text { for the } i^{\text {th }} \text { record in the } j^{\text {th }}\right. \text { plot }
$$

Met $R^{2}$ adj $=0.788$ werd gevonden $c_{13}=0.2308$ in een $95 \%$ betrouwbaarheidsinterval $\{0.1897 ; 0.2791\}$, de gemiddelde $S \%$ waarde per plot is 21 met een range $\{15 ; 27\}$.

In de beschikbare opbrengsttabellen voor Nederland (Faber, 1996) is deze waarde 0.2632.

De dunninggraden hebben dus niet langer een vast maar een variabel $S \%$.

Jansen et al. (2016) voorspellen de diameter na dunning met een modificatie van het model van La Bastide \& Faber (1972): 


$$
\begin{aligned}
d_{a t}= & d_{b t} \cdot\left\{R \cdot \frac{a_{a t}}{a_{b t}}+1-R\right\} \\
& \text { where } R=c_{14}+c_{15} \cdot h_{70}+c_{16} \cdot \sqrt{T g r}+c_{17} \cdot t
\end{aligned}
$$

Met een $R^{2}$ adj van 0.999 werden de parameters van Tabel 7 gevonden.

Tabel 7. Parameterschatting met Model (14).

Table 7. Parameter estimation with Model (14).

\begin{tabular}{|l|r|r|r|r|}
\hline & & & \multicolumn{2}{|c|}{ 95\% Confidence Interval } \\
\cline { 4 - 5 } Parameter & Estimate & Std. Error & Lower Bound & Upper Bound \\
\hline$c_{14}$ & 1.0091 & 0.137 & 0.738 & 1.281 \\
$c_{15}$ & -0.0108 & 0.005 & -0.020 & -0.002 \\
$c_{16}$ & -0.1251 & 0.030 & -0.183 & -0.067 \\
$c_{17}$ & -0.0040 & 0.001 & -0.005 & -0.003 \\
\hline
\end{tabular}

Bij de analyse zijn alle opnamen uitgesloten waarbij er minder dan 4 bomen uit het proefperk waren verdwenen, omdat dit meestal geen dunning maar sterfte betreft. Ook opnamen waarbij de diameter voor dunning hoger was dan die na dunning zijn uitgesloten, omdat dit geen normale laagdunning betreft. Door die selectie zijn er 169 waarnemingen beschikbaar.

Bij het maken van de opbrengsttabellen zal extrapolatie naar gebieden die niet gedekt zijn door data noodzakelijk zijn. Daarom is ook het originele model van La Bastide \& Faber gefit:

$$
d_{a t}=d_{b t} \cdot\left\{c_{18} \cdot \frac{a_{a t}}{a_{b t}}+1-c_{18}\right\}
$$

Met een $R^{2}$ adj van 0.998 werd voor de parameter gevonden $c_{18}=0.3152$ in een $95 \%$ betrouwbaarheidsinterval $\{0.297 ; 0.333\}$. Achteraf bleek het niet nodig model (15) te gebruiken. 


\section{Constructie Opbrengsttabellen}

Met de in deze studie gevonden relaties zal nu een nieuwe opbrengsttabel worden gemaakt met één dunninggraad.

Al eerder is besloten een indeling in relatieve boniteiten te maken, met daaraan gekoppeld de "hoogte" op 70 jaar. Er is gekozen voor de volgende presentatie van gegevens op dezelfde wijze als voor de douglas door Jansen et al. (2016). Er zijn echter geen data beschikbaar om de dominante hoogte en dominante diameter te bepalen, dus deze gegevens komen niet meer voor in deze opbrengsttabellen.

Voor een groot aantal van deze gegevens kunnen de gevonden relaties in de voorafgaande hoofdstukken worden gebruikt. Maar er zullen nog wat allometrische relaties gefit moeten worden, voor variabelen die tot nu toe nog niet voorkwamen.

\subsection{Overige allometrische relaties}

\section{Gemiddelde opstandhoogte}

Jansen et al. (2016) vonden voor de gemiddelde hoogte $\left(h_{g}\right)$ na dunning een powerfunctie gevonden met in de loop van de ontwikkeling wijzigende parameters:

$$
\begin{aligned}
& h_{a t}= \begin{cases}h_{a t(2)} & \text { for } h_{\text {top }} \leq 1.30 \mathrm{~m} \\
h_{a t(2)} & \text { for } h_{a t(1)} \leq h_{a t(2)} \\
h_{a t(1)} & \text { else }\end{cases} \\
& \text { where } h_{a t(1)}=\left(c_{19}+c_{20} \cdot a g e\right) \cdot h_{t o p}^{\left(c_{21}-c_{22} \cdot h_{\text {top }}\right)} \\
& h_{a t(2)}=c_{23} \cdot h_{\text {top }} \text { and } c_{23}=0.8 \text { (a set value) }
\end{aligned}
$$

Met een $R^{2}$ adj van 0.986 werden de volgende parameters gevonden: $c_{19}=0.6379, c_{20}=$ $0.0001179, c_{21}=1.1504$ en $c_{22}=0.0008994$. De begrenzing met de $c_{23}$ parameter is achteraf ingesteld omdat de basisformule voor lage leeftijden onrealistische waarden opleverde.

Voor de hoogte voor dunning volgde:

$$
h_{b t}=c_{24} \cdot h_{a t} \quad \text { with } R^{2} \text { adj }=0.996 \text { and } c_{24}=0.9918
$$

\section{Opstandvolume}

In de data zijn de boomvolumes bepaald met de Formule (18), zie Dik (1984). Ze gebruikte het Schumacher-Hall-model (1933):

$$
v=d^{c_{25}} \cdot h^{c_{26}} \cdot e^{c_{27}} \text { met } d \text { in } \mathrm{cm}, h \text { in m en } v \text { in } \mathrm{dm}^{3}
$$

Voor Amerikaanse eik geldt: $c_{25}=1.95645, c_{26}=0.88671$ en $c_{27}=-2.76750$.

Formule (18) is niet geschikt om het opstandvolume te bepalen. In het verleden werd gebruik gemaakt van de gemodificeerde opstandvolumefunctie van Heisterkamp (1981), de functie luidt: 


$$
\begin{aligned}
V= & c_{28} \cdot G^{c_{29}} \cdot h_{\text {top }}^{\left(c_{30}+c_{31} \cdot t_{0}\right)} \text { with } G \text { in } \mathrm{m}^{2} / \mathrm{ha}, h_{\text {top }} \text { in } \mathrm{m} \text { and } V \text { in } \mathrm{m}^{3} / \text { ha } \\
& \text { where } t_{0}=t-t_{1.30}
\end{aligned}
$$

Met een $R^{2}$ adj van 0.989 werden de volgende parameters gevonden: $c_{28}=0.8824, c_{29}=$ $0.9294, c_{30}=0.8583$ en $c_{31}=-0.000286$.

De formule van Heisterkamp is ontwikkeld voor opbrengsttabellen die een startwaarde hadden voor de opperhoogte, voor Amerikaanse eik was die $7 \mathrm{~m}$. Daar beneden moet met de Formule (18) worden gewerkt.

\section{Beginstamtal}

Als beginstamtal is gekozen voor $5000\left(=c_{32}\right)$ en 3000 bij een open stand.

\section{Grenswaarde}

De steeds terugkerende grenswaarde voor de opperhoogte van $7 \mathrm{~m}$ is de parameter $c_{33}$ in de modellen. En geeft daarbij de boven grens aan voor de jeugdgroei.

\subsection{Opbrengsttabellen}

Allereerst is gekozen welke tabellen gepubliceerd zullen worden. Er is gekozen voor een opbrengsttabel voor Nederland met één dunninggraad en vijf boniteiten.

In Tabel 9 is de verdeling over boniteiten en leeftijdsklassen gegeven voor het aantal opstanden in de $4^{\mathrm{e}}$ Bosstatistiek met een leeftijd vanaf 12 jaar in Nederland. Dit geeft de behoefte aan tabellen weer, terwijl Tabel 8 een indicatie van de mogelijkheden geeft.

Tabel 8. Leeftijdsinterval in dataset per dunninggraad en boniteit.

Table 8. Age interval in the data set by thinning grade and site class.

\begin{tabular}{|l|ccccc|}
\hline & \multicolumn{4}{|c|}{ leeftijdsinterval per boniteit } \\
\hline Dunninggraad & I & II & III & IV & V \\
\hline zonder dunning & & $24-35$ & $35-46$ & & \\
zwakke laagdunning & & $25-88$ & $36-91$ & & \\
matige laagdunning & $27-71$ & $8-65$ & $26-88$ & $65-110$ & \\
sterke laagdunning & $37-61$ & $20-83$ & $23-60$ & & \\
zeer sterke laagdunning & $37-60$ & $25-72$ & $25-61$ & & $54-71$ \\
open stand & & $25-39$ & $17-64$ & & \\
\hline
\end{tabular}

Extrapolatie buiten het waarnemingsmateriaal moet in principe beperkt worden maar is onvermijdelijk (zie Tabel 8). De maximale leeftijd is op 100 jaar gesteld. 
Tabel 9. Aantal opstanden per leeftijdsklassen en boniteit in $4^{\mathrm{e}}$ Bosstatistiek $\left(\boldsymbol{h}_{\text {top }}>7 \mathrm{~m}\right)$.

Table 9. Age classes per site class in $4^{\text {th }}$ National Forest Inventory (number of stands).

\begin{tabular}{|c|rrrrr|r|}
\hline leeftijdsklasse & $\mathbf{S}$ & II & III & IV & $\mathbf{\geq ~ V}$ & totaal \\
\hline $10-20$ & 17 & 90 & 47 & 14 & 1 & 169 \\
$20-30$ & 39 & 250 & 140 & 43 & 8 & 480 \\
$30-40$ & 54 & 296 & 260 & 79 & 12 & 701 \\
$40-50$ & 59 & 202 & 300 & 150 & 53 & 764 \\
$50-60$ & 38 & 105 & 177 & 98 & 34 & 452 \\
$60-70$ & 20 & 55 & 84 & 46 & 13 & 218 \\
$70-80$ & 13 & 27 & 52 & 34 & 22 & 148 \\
$80-90$ & 8 & 12 & 14 & 14 & 3 & 51 \\
$90-100$ & 4 & 3 & 5 & 9 & 5 & 26 \\
$\geq 100$ & 2 & 3 & 3 & 8 & 2 & 18 \\
\hline Totaal & 254 & 1043 & 1082 & 495 & 153 & 3027 \\
\hline
\end{tabular}

Er zal één tabel voor Amerikaanse eik met een matige laagdunning worden gemaakt.

Jansen et al. (2016) geven voor de douglas hoe deze geconstrueerd wordt. Deze werkwijze is gevolgd, uiteraard met aanpassing voor afwijkende onderdelen.

In Tabel 10 is een lijst met de geschatte parameters opgenomen. 
Tabel 10. Lijst met alle parameters.

Table $10 . \quad$ List with all parameters.

\begin{tabular}{|l|rr|}
\hline Parameter & Formula number & Thinning from below \\
\hline$c_{1}$ & $(7)$ & 0.0199126 \\
$c_{2}$ & $(7)$ & 5.2935829 \\
$c_{3}$ & $(7)$ & 0.1461847 \\
$c_{4}$ & $(9)$ & 1 \\
$c_{5}$ & $(9)$ & -2.7904851 \\
$c_{6}$ & $(9)$ & 0.1216332 \\
$c_{7}$ & $(9)$ & 2.6566876 \\
$c_{8}$ & $(11)$ & 4.0326302 \\
$c_{9}$ & $(11)$ & 0.0821071 \\
$c_{10}$ & $(11)$ & 19.1176632 \\
$c_{11}$ & $(11)$ & 0.7262387 \\
$c_{12}$ & $(11)$ & 0.2906659 \\
$c_{13}$ & $(12)$ & 0.2307776 \\
$c_{14}$ & $(14)$ & 1.0091407 \\
$c_{15}$ & $(14)$ & -0.0108162 \\
$c_{16}$ & $(14)$ & -0.1250919 \\
$c_{17}$ & $(14)$ & -0.0039512 \\
$c_{18}$ & $(15)$ & 0.8715925 \\
$c_{19}$ & $(16)$ & 0.6378945 \\
$c_{20}$ & $(16)$ & 0.0001179 \\
$c_{21}$ & $(16)$ & 1.1504443 \\
$c_{22}$ & $(16)$ & 0.0008994 \\
$c_{23}$ & $(16)$ & 0.8000000 \\
$c_{24}$ & $(17)$ & 0.9917606 \\
$c_{25}$ & $(18)$ & 1.8393200 \\
$c_{26}$ & $(18)$ & 0.9724000 \\
$c_{27}$ & $(18)$ & -2.7187700 \\
$c_{28}$ & $(19)$ & 0.8823818 \\
$c_{29}$ & $(19)$ & 0.9294221 \\
$c_{30}$ & $(19)$ & 0.8583376 \\
$c_{31}$ & $(19)$ & -0.0002857 \\
$c_{32}$ & $N_{0}$ & 5000 \\
$c_{33}$ & & 7 \\
\hline
\end{tabular}

In Paragraaf 6.3 worden enkele eigenschappen van de uiteindelijk tabellen vergeleken met andere opbrengsttabellen. In Bijlage 1 is de geproduceerde opbrengsttabel weergegeven.

\subsection{Vergelijking met andere opbrengsttabellen}

Hierna zijn enkele andere opbrengsttabellen voor de Amerikaanse eik in Europa vergeleken met het hier gevonden resultaat, dat betreffen de tabel voor België van Laurent et al. (1988), de tabel van Bauer (1953) voor Duitsland en die van Faber (1996) voor Nederland. 


\subsubsection{Hoogteontwikkeling}

Laurent et al. onderscheiden maar 2 boniteiten, waarvan de $\mathrm{II}^{\mathrm{e}}$ boniteit tussen 20 en 70 jaar zeer goed overeenkomt met de $\mathrm{II}^{\mathrm{e}}$ boniteit van de nieuwe tabel voor Nederland, na 70 jaar vlak hun groei nauwelijks af. De I $\mathrm{I}^{\mathrm{e}}$ boniteit vertoont een iets steilere groei (zie Figuur 9).

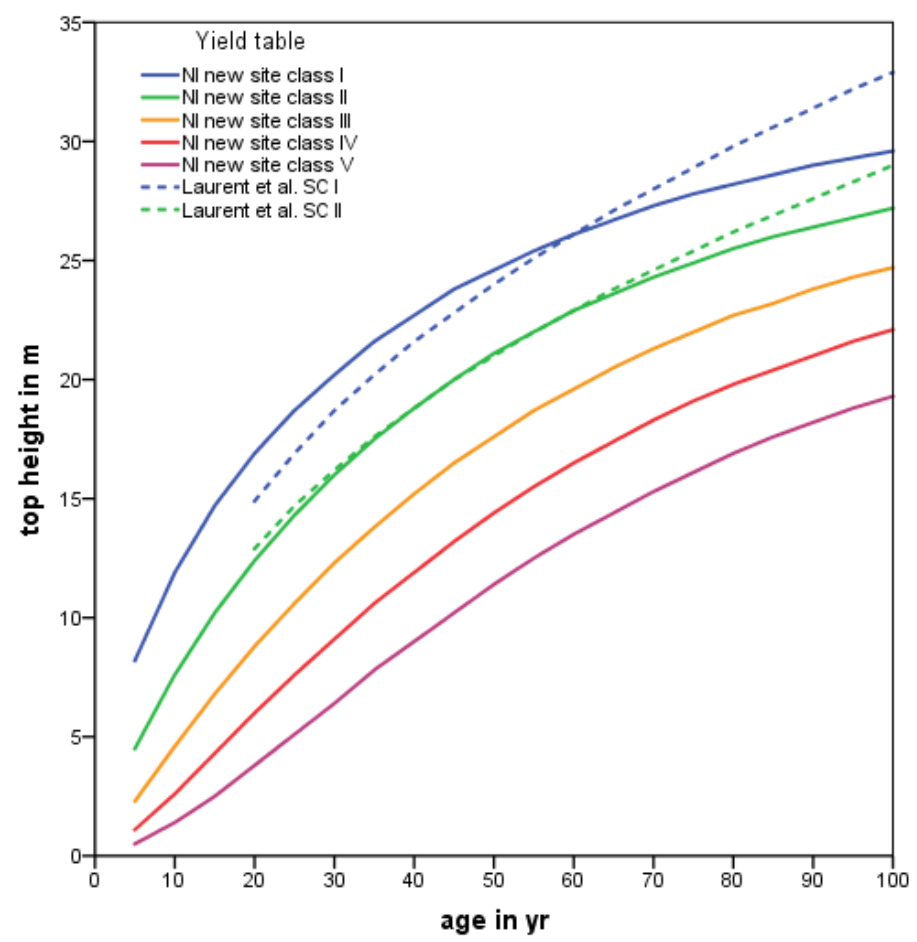

Figuur 9. Hoogteontwikkeling bij Laurent et al. en het nieuwe model voor Nederland.

Figure 9. Height development at Laurent's et al. yield table and the new model for Netherlands.

Bauer onderscheidt maar 3 boniteiten. De hoogteontwikkeling komt bij Bauer veel langzamer op gang, en vertonen daarna een steilere groei (zie Figuur 10). 


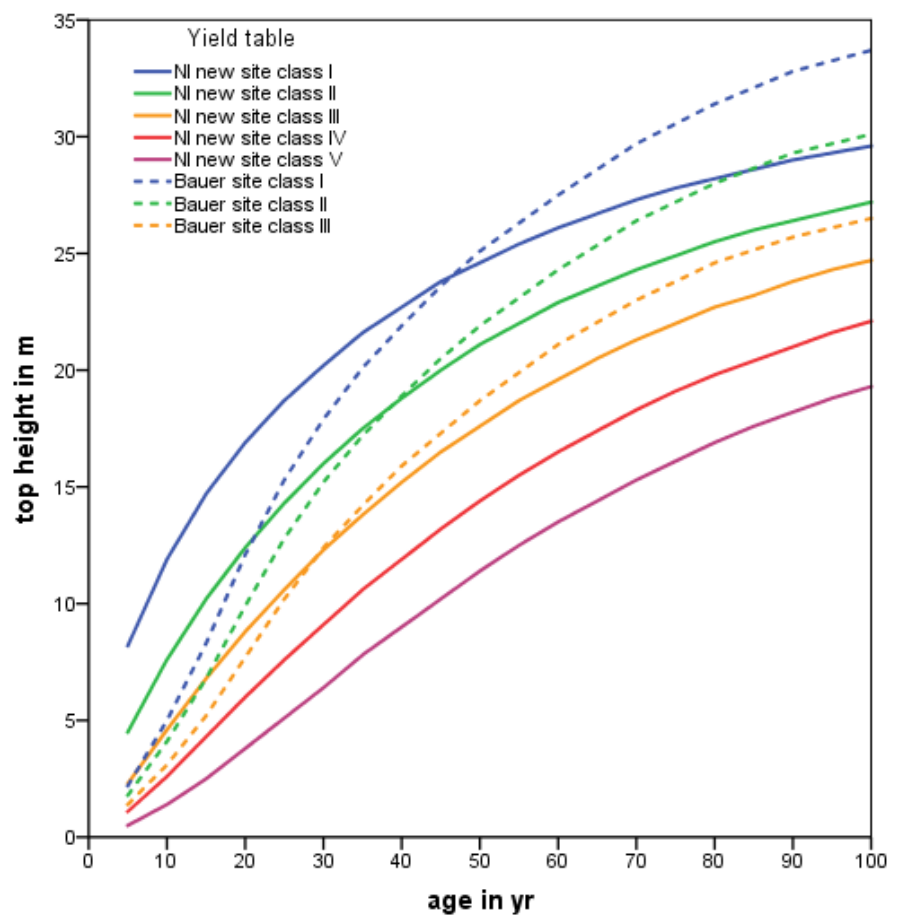

Figuur 10. Hoogteontwikkeling bij Bauer en het nieuwe model voor Nederland.

Figure 10. Height development at Bauer's yield table and the new model for Netherlands.

De hoogtecurven bij Faber (1996) komen voor de productieklassen 7 en 8 zeer goed overeen met de II boniteit van de nieuwe tabellen voor Nederland (zie Figuur 11). De slechtere boniteiten vlakken er eerder af en hebben een snellere jeugdgroei.



Figuur 11. Hoogteontwikkeling bij Faber en het nieuwe model voor Nederland.

Figure 11. Height development at Faber's yield table and the new model for Netherlands. 


\subsubsection{Productieniveau}

Het productieniveau wordt bij voorkeur gemeten op basis van de gemiddelde volumebijgroei bij zekere leeftijd. Hier is echter naar de totale grondvlakproductie gekeken.

In Figuur 12 is de totale grondvlakproductie per opbrengsttabel uitgezet tegen de opperhoogte voor alle boniteiten. De meeste opbrengsttabellen hebben als startpunt een hoogte van tussen 6 en $16 \mathrm{~m}$, en de nieuwe tabel vanaf $1.3 \mathrm{~m}$.

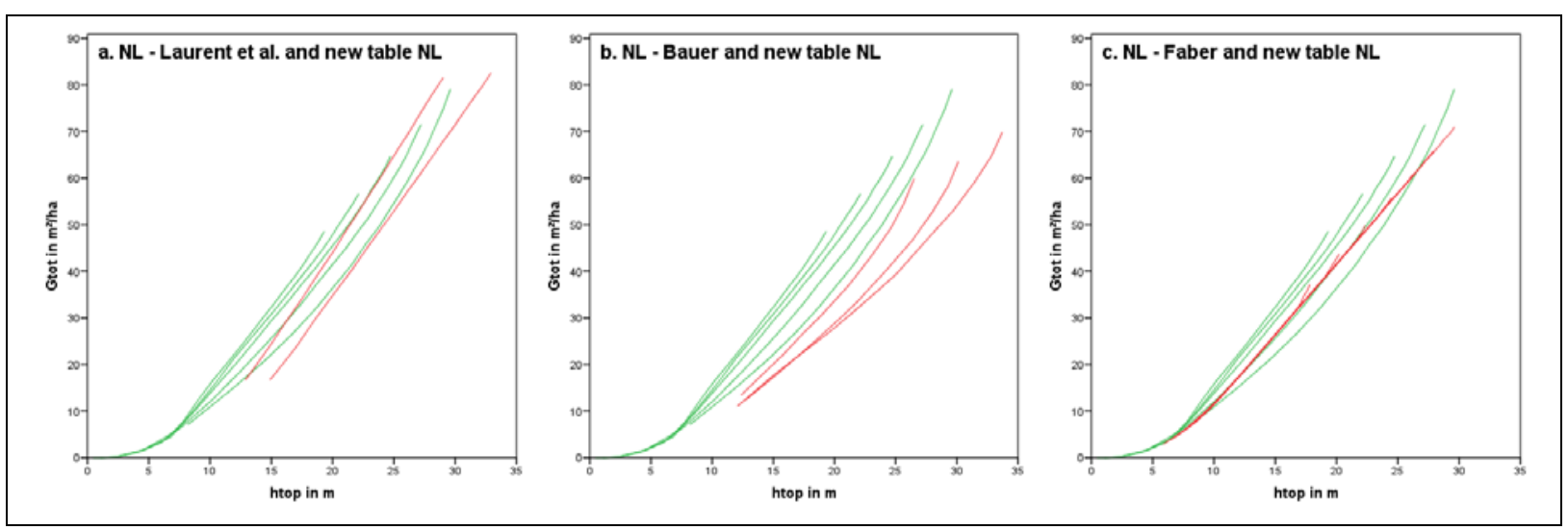

Figuur 12. De totale grondvlakproductie Gtot in relatie tot de opperhoogte bij de nieuwe tabel voor Nederland (in groen) in vergelijking met andere opbrengsttabellen (in rood) voor Laurent (a), Bauer (b) en Faber (c).

Figure 12. Total basal area production Gtot in relation to top height for the new table for the Netherlands (in green) in comparison with other yield tables (in red) from laurent (a), Bauer (b) and (c).

De hellinghoeken van alle tabellen komen redelijk overeen met die van de nieuwe tabel. De tabellen van Bauer hebben lager productieniveau dan de nieuwe tabel. 


\section{Discussie en conclusies}

\subsection{Hoogtegroei}

De hoogteontwikkeling van de opstand is een resultante van hoogtegroei en topsterfte. Een biologisch relevant groeimodel moet een buigpunt en een asymptoot hebben. Het model van Jansen-Hildebrand (1986) voldeed het best:

$$
h_{\text {top }}=S \cdot\left(1-e^{-c_{1} \cdot t}\right)^{b} \quad \text { where } b=c_{2}-c_{3} \cdot S
$$

De asymptoot, hier de site index $S$ genoemd, is een maat voor de geschiktheid van de standplaats (boniteit) voor de Amerikaanse eik, in de praktijk wordt echter $h_{70}$ als maat voor de boniteit gebruikt. Boniteren is met dit model lastig, want vereenvoudigd volgt uit Formule (20) voor de inverse functie $g$ van (20) $S=g\left(s, t, h_{\text {tot }}\right)$, je moet dus met een startwaarde voor $S$ werken en iteratief naar een oplossing werken als volgt:

$$
\begin{aligned}
& \rightarrow S_{\text {new }}=h_{\text {top }} \cdot\left(1-e^{-c_{1} \cdot t}\right)^{-b} \quad \text { where } b=c_{2}-c_{3} \cdot S_{\text {old } 1} \\
& \rightarrow S_{\text {old } 2}=\left(3 \cdot S_{\text {old } 1}+S_{\text {new }}\right) / 4
\end{aligned}
$$

Dit herhalen tot $S=S_{\text {new }}=S_{\text {old }}$ en vervolgens volgt $h_{70}=f_{26}(S, 70)$

De $R^{2}$ adj bleek met een waarde van 0.970 vrij laag. De jeugdgroei van de beste boniteiten hebben geen buigpunt en lijken onwaarschijnlijk, maar konden door gebrek aan waarnemingen niet verbeterbaar.

\subsection{Diameter en grondvlak}

In Paragraaf 4.2 is het model voor de lopende bijgroei van het grondvlak ontwikkeld. Dit model start na het bereiken van een opperhoogte van $7 \mathrm{~m}$. In Paragraaf 7.2.2 wordt hierop ingegaan. Om een startwaarde voor de diameter voor dunning en het grondvlak per ha voor dunning te hebben op het tijdstip $t_{7}$ is in Paragraaf 4.1 een model ontwikkeld voor de diameterontwikkeling. In Paragraaf 7.2.1 wordt dit besproken.

\subsubsection{Diameterontwikkeling}

In Paragraaf 4.1 is een nieuw model voor de diameterontwikkeling gebruikt, in vereenvoudigde vorm luidt dit:

$$
\begin{gathered}
d_{b t}=f_{2}\left(h_{t o p}, d_{7}\right) \text { for } h_{\text {top }} \leq 7 \\
\text { where } d_{7}=f_{1}\left(h_{t o p}, a_{b t}\right) \quad \text { (the diameter at a height of } 7 \mathrm{~m} \text { ) } \\
a_{b t}=\text { trees distance before thinning }
\end{gathered}
$$


In alle vergeleken opbrengsttabellen is dit traject niet beschreven en starten de tabellen bij de eerste dunning in de buurt van een hoogte van $7 \mathrm{~m}$. In Figuur 12 is te zien dat die beginwaarden voor $G_{b t}$ bij de tabellen van Faber (1996) voor Nederland en van Laurent (1988) goed overeenkomen met de berekende waarde via $G_{7 \_b t}=N_{0} \cdot \pi \cdot\left(d_{7} / 200\right)^{2}$ en $d_{7}$ uit Formule (22). De tabel van Bauer wijkt daarvan af met een lager productieniveau.

\subsubsection{Grondvlakbijgroei}

In Paragraaf 4.2 werd Formule (11) voor de grondvlakbijgroei gevonden, in vereenvoudigde vorm luidt dit:

$$
\begin{aligned}
i_{G, i j k}= & f_{1}(S \%) \cdot\left\{\frac{F_{3}\left(h_{2}, t_{2}\right)-F_{3}\left(h_{1}, t_{1}\right)}{t_{2}-t_{1}}\right\} \\
& \text { for the } j^{\text {th }} \text { plot at age } i=t_{m}=\left(t_{1}+t_{2}\right) / 2 \text { in the } k^{\text {th }} \text { year of recording }
\end{aligned}
$$

Een power-functie voor $F_{3}$ het meest geschikt. Net als bij de douglas (Jansen et al. 2016) stijgt de grondvlakbijgroei met toenemende boniteit, de stijging is alleen een gevolg van $F_{3}$. Die stijging bleek ongeveer gelijk aan die in de vigerende opbrengsttabellen van Faber (1996) De correctiefactor voor de grondvlakbijgroei $f_{1}$ is actief vanaf een $S \%$ van ongeveer $19 \%$.

\subsection{Dunning}

Om de dunning te kwantificeren is een dunninggraad gebruikt. De in Duitsland gebruikelijke indeling met een A- tot en met D-graad gebaseerd op het dunnen van bomen behorend tot een of meerdere Kraftse boomklassen is in Nederland nooit aangeslagen. Becking (1953) vindt deze methode te weinig kwantitatief en kiest voor een $S$ \% (volgens Hart, 1928) van 16 $\%$ voor een zwakke laagdunning, met $3 \%$ erbij is dan sprake van de volgende dunninggraad, namelijk bij $19 \%$ een matige laagdunning. In Tabel 6 is een volledig overzicht van het $S \%$ en de bijbehorende namen. In andere opbrengsttabellen is een geleidelijk toename een bepaald $S \%$ te zien vanaf ongeveer 35 jaar. Dit is logisch omdat op latere leeftijd de kroonvorm verandert, waardoor bij gelijkblijvende standruimte een hogere $S \%$ nodig is. De mate van deze verandering is geschat en vergeleken met andere opbrengsttabellen en in Formule (12) weergegeven. Het ratiomodel (14) van La Bastide en Faber (1972) is gebruikt in gemodificeerd vorm, waarbij de ratio afhankelijk is van de boniteit, de dunninggraad en leeftijd.

\subsection{Kwaliteit van het model}

In Tabel 11 is de groeiklasse per boniteit aangegeven. Deze groeiklasse is het totaal geproduceerde (en deels geoogste) gemiddelde spilhoutvolume in $\mathrm{m}^{3} \mathrm{ha}^{-1} \mathrm{jr}^{-1}$ bij een leeftijd van 70 jaar. 
Tabel 11. Groeiklasse per dunninggraad en boniteit.

Table 11. Yield class (mean annual volume increment at 70 yr.) per thinning grade and site class.

\begin{tabular}{|l|rrrrr|}
\hline \multirow{2}{*}{ Dunninggraad } & \multicolumn{5}{|c|}{ Boniteit } \\
& I & II & III & IV & V \\
\hline matige laagdunning & 9.0 & 7.2 & 5.7 & 4.3 & 3.0 \\
\hline
\end{tabular}

In Tabel 3 blijkt dat het totale bereik voor de $h_{70} 13.8$ tot $28.8 \mathrm{~m}$ bedraagt voor de boniteiten I tot V. In de $4^{\mathrm{e}}$ Bosstatistiek bleek de slechts groeiende opstand een $h_{70}$ van 8.9 te hebben en de beste 32.0 , de groeiklasse zou dan respectievelijk 0.6 en $10.3 \mathrm{~m}^{3} \mathrm{ha}^{-1} \mathrm{jr}^{-1}$ bedragen.

Volgens https://www.monumentaltrees.com/nl/hoogterecords/nld/ (geraadpleegd 15-112017) staat de hoogste Amerikaanse eik ( 40.0 m met een leeftijd van ca 117 jaar) van Nederland in Sonsbeek te Arnhem, een solitaire boom in een hoger beuken bos. De $h_{70}$ van een opstand met gelijke hoogte en leeftijd laat zich niet berekenen omdat de $S$-waarde dan groter dan 40.0 m moet zijn waarmee de b-prameter van Formule (7) negatief. De parametercombinatie van model (7) staat een maximale $S$-waarde toe van 36.2. Volgens dezelfde site zijn er elders in Europa Amerikaanse eiken die hoger zijn. De hoogste $S$-waarde in de $4^{\mathrm{e}}$ bosstatistiek bleek 34.4 m. De kans dat er standplaatsen in Nederland zijn waar het groeimodel niet toepasbaar is lijkt daarom onwaarschijnlijk. 


\section{Samenvatting}

Dit is een rapport over de groei en productie van de Amerikaanse eik (Quercus rubra) in Nederland. Er is onderzocht hoe de ontwikkeling van de hoogte, diameter en het grondvlak in de tijd is geweest en hoe deze beïnvloed wordt door de dunning. Met de gevonden relaties en andere allometrische relaties is een opbrengsttabellen opgesteld voor gelijkjarige opstanden van Amerikaanse eik.

De gebruikte dataset betreft de gegevens die tussen 1949 en 1988 in Nederland in groei- en productieonderzoek bij de Amerikaanse eik zijn verzameld door diverse bosbouwonderzoekgroepen die nu alle tot de WUR behoren; dit omvat 37 proefperken. Daarnaast zijn 21 plots uit de $4^{\mathrm{e}}$ bosstatistiek, en later de HOSP, gebruikt. In totaal betreft het 58 plots met 306 opnamen gebruikt. Per opname zijn leeftijd, opnamedatum en opperhoogte bekend en per toestand voor, na en van de dunning stamtal, grondvlak, diameter, hoogte en volume.

De hoogteontwikkeling is onderzocht met vier bekende groeimodellen en bleek het best te verklaren met het model van Jansen \& Hildebrand. (1986), een variant van de Chapman-Richards functie: $h_{\text {top }}=S \cdot\left(1-e^{-c_{1} \cdot t}\right)^{b}$ met $b=c_{2}-c_{3} \cdot S$. Hierin is $S$ een proefperkspecifieke parameter en maat voor een absolute hoogteboniteit, $c_{1}, c_{2}$ en $c_{3}$ zijn soortspecifieke parameter die de vorm van de curven bepalen. Hiermee wordt een heteromorf stelsel van hoogtegroeicurven gecreëerd. Voor het totale model werd een $R^{2}$ adj van 0.970 gevonden, wat voor een hoogtegroeimodel relatief laag is.

De hoogteontwikkeling bij de vergeleken tabellen van Laurent et al. (1988), Bauer (1953) en Faber (1996) komt goed overeen met die van de nieuwe tabel.

De diameterontwikkeling tot een hoogte van $7 \mathrm{~m}$. werd het best verklaard met het model van Jansen et al. (2016) $d_{b t}=d_{7} \cdot f\left(h_{t o p}\right)$. Bij gebrek aan data is een lineaire functie is gebruikt. Voor het schatten van $d_{7}$ werd een nieuwe formule ontwikkelt: $d_{b t}=c_{5}+c_{6} \cdot h_{t o p}^{1.5}+c_{7} \cdot a_{b t}$, met $a_{b t}$ de gemiddelde boomafstand, hier voor zijn alleen opnamen met leeftijd tot 35 jaar gebruikt. Door het invullen van een hoogte van $7 \mathrm{~m}$ volgt $d_{7}=f\left(N_{0}\right)$. De $R^{2}$ adj bleek 0.934 en $d_{7}=3.5 \mathrm{~cm}$ bij $N_{0}=5000$. Voor het traject boven een hoogte van $7 \mathrm{~m}$ is de grondvlakbijgroei gemodelleerd met een ander model van Jansen et al. (2016): $i_{G}=f\left(h_{\text {top }}, t, S \%\right.$, yor $)$ waarbij gebruik gemaakt is van een powermodel. Voor $S \%>19.1$ daalt de grondvlakbijgroei niet-lineair met gemiddeld $2.6 \%$ per $S \%$ verschil. De $R^{2}$ adj is 0.458 . Het jaar van opname (yor) bleek niet significant. Het model is in strijd met de wet van Eichhorn.

Het effect van de dunning op de diameter na dunning $\left(d_{a t}\right)$ is gemodelleerd met een modificatie van het La Bastide-Faber model (1972).

Met de geïntegreerde modellen is een opbrengsttabel gemaakt voor een leeftijd tot 100 jaar met 5 boniteiten. Deze tabel is vergeleken met tabellen uit België en Duitsland en die van Faber (1996) voor Nederland. Het productieniveau bij Laurent et al. (1988) voor België en dat van de tabel van Faber voor Nederland komt goed overeen met dat van de nieuwe tabel voor Nederland. Het productieniveau bij Bauer (1953) voor Duitsland was veel lager.

Op hoofdlijnen bleek het model van Jansen et al. (2016) voor de douglas ook bruikbaar voor de Amerikaanse eik. 


\section{Summary}

This report describes growth and yield of red oak (Quercus rubra) in Netherlands. The report deals with development of the height, diameter and basal area over time, based on permanent field plots, and how these characteristics are affected by thinning. The regularities and allometric relationships found, were used to construct a yield table for even-aged stands of red oak.

The dataset used in this study is composed of all growth and yield related research on red oak in the Netherlands, carried out between 1949 and 1988 by various forestry research groups, now all part of Wageningen University and Research (WUR), and includes 37 experimental plots. Furthermore, 21 plots from the 4th Dutch National Forest Inventory and from the timber prognosis system HOSP, were used. In total, the dataset consists of 58 plots with 306 recordings. Each plot record includes age, recording date and top height, as well as stem density, basal area, diameter, height and volume before and after thinning and of the thinning itself.

Height development was analysed using four well-known equations, and the best fit was found with Jansen \& Hildebrand's model (1986); this polymorphic model is given by: $h_{\text {top }}=S \cdot\left(1-e^{-c_{1} \cdot t}\right)^{b}$ where $b=c_{2}-c_{3} \cdot S$. Here, $S$ is a plot specific parameter and a measure for site index, and $c_{1}, c_{2}$ and $c_{3}$ are species-specific parameters that determine the shape of the curve. For practical use the height at an age of 70 year $\left(h_{70}\right)$ is chosen as site index. With non-linear regression (NLR) a solution was found with, for a height growth model, a rather low $R^{2}$ adj of 0.970 .

The height development was compared with those of the yield tables by Laurent et al. (1988), Bauer (1953) and Faber (1996). There was a very good match with all compared tables.

The diameter development (before thinning: $d_{b t}$ ) to a height of $7 \mathrm{~m}$ was explained by the model of Jansen et al. (2016) $d_{b t}=d_{7} \cdot f\left(h_{\text {top }}\right)$, Missing data in the desired range were replaced by a linear function $f$ instead of a power or Gompertz function. Also for the diameter at a height of $7 \mathrm{~m}\left(d_{7}\right)$ another function was used: $d_{b t}=c_{5}+c_{6} \cdot h_{t o p}^{1.5}+c_{7} \cdot a_{b t}$, for stands with an age up to 35 year. With $N_{0}=5000, d_{7}$ is $3.5 \mathrm{~cm}$. The $R^{2}$ adj was 0.934 . The model was only used for diameter and basal area development up to a height of $7 \mathrm{~m}$. For the development above $7 \mathrm{~m}$ height, basal are increment was expressed using the model of Jansen et al (2016): $i_{G}=f\left(h_{t o p}, t, S \%, y o r\right)$, using a power function. For the Becking-Hart spacing index $S \%>19.1$ the basal area increment decreased nonlinearly relative to $S \%$ with $2.6 \%$ per unit. The $R^{2}$ adj was 0.458 . The year of recording (yor) was not significant. The model does not follow Eichhorn's law.

The effect of thinning on diameter after thinning $\left(d_{a t}\right)$ was modelled with a modification of the La Bastide-Faber model (1972)

Using the integrated models, a yield table was created for even-aged stands of ages up to 100 years, using five site classes. The yield table was compared with tables from Belgium and Germany, and with those published by Faber (1996) for The Netherlands. The production 
level of Laurent's et al. (1988) for Belgium and of Faber's for the Netherlands matched very well with those of the new tables for the Netherland. The production level at Bauer's table (1953) for Germany was much lower.

Overall, the model of Jansen et al. (2016) for Douglas fir turned out to be suitable also for red oak. 


\section{Literatuur}

Bartelink, H.H., A.F.M. Olsthoorn, A. Oosterbaan \& S.M.J. Wijdeven, 2001. Overzicht van een eeuw onderzoek naar groei en opstandsontwikkeling in relatie tot groeiplaats en beheer. Alterra, Research Instituut voor de Groene Ruimte, Wageningen, Alterrarapport 256.

Bauer, F., 1953. Die Roteiche J.D. Sauerländer's Verlag, Frankfurt a. M.

Becking, J. H., 1953. Thinning research in forestry. Netherlands Journal of Agricultural Science; 1953. 1(2):122-9.

Burkhart, H,E. \& R.B. Tennent, 1977. Site index equations for radiata pine in New Zealand. New Zealand Journal of Forestry Science 7: 408416.

C.B.S. (Centraal Bureau voor de Statistiek),1985. De Nederlandse Bosstatistiek, deel 1: de oppervlakte bos,1980 1983. Staatsuitgeverij, s'Gravenhage

Cieszewski C.J., 2001. Three methods of deriving advanced dynamic site equations demonstrated on inland Douglas-fir site curves. Can. J. For. Res. 31: 165-173 .

Dik, E.J., 1984. De schatting van het houtvolume van staande bomen van een aantal in de bosbouw gebruikte soorten. Uitvoerig verslag Rijksinstituut voor onderzoek in de bos en landschapsbouw "De Dorschkamp" Band 19(1), Wageningen.

Faber, P.J., 1996. Opbrengsttabel voor de Amerikaanse eik (Quercus rubra L.) in Nederland. In: Jansen, J.J., J. Sevenster \& P.G. Faber (editors) (1996). Opbrengsttabellen voor belangrijke boomsoorten in Nederland. IBN rapport 96, p 91-98.

Hart, H.M.J., 1928. Stamtal en dunning : een orienteerend onderzoek naar de beste plantwijdte en dunningswijze voor den djati. Proefschrift Wageningen. Mededeelingen Proefstation voor het Boschwezen (21) 219 p. + 7 bijl. Veenman, Wageningen.

Heisterkamp, S.H., 1981. Opstandsinhoudsfuncties. Rapport Rijksinstituut voor onderzoek in de bos- en landschapsbouw "De Dorschkamp" 271, Wageningen.

IUFRO, 1959. The standardization of symbols in forest mensuration. International Union of Forest Research Organizations, Londen.

Jansen, J.J. \& J.W. Hildebrand, 1986. Een nieuwe opbrengsttabel voor de fijnspar (Picea abies Karst.) in Nederland. Landbouwhogeschool, Vakgroep Boshuishoudkunde, Wageningen.

Jansen, J.J., J. Sevenster \& P.G. Faber (redactie), 1996. Opbrengsttabellen voor belangrijke boomsoorten in Nederland. IBN rapport 96/Hinkeloord reports No.17, 202 pag.

Jansen, J.J., H. Schoonderwoerd, G.M.J. Mohren \& J. den Ouden, 2016. Groei en productie van douglas in Nederland. Becking's dunningproeven ontsloten. Wageningen Academic Publishers.

La Bastide, J.G.A. \& P.J. Faber, 1972. Revised yield tables for six tree species in the Netherlands. Uitvoerig Verslag Bosbouwproefstation "De Dorschkamp", band 11, nr. 1.

Laurent C., J. Rondeux \& A. Thill, 1988, Production du chêne rouge d'Amérique (Quercus rubra L.) en Moyenne et Haute Belgique. Forêts, Nature et Paysage > Gestion des ressources forestières et des milieux naturels

Oosterbaan A., J.J. Jansen, J.F. Oldenburger, G.M. Mohren \& J. den Ouden, 2016. FEM growth and yield data Monocultures - Red oak. DANS. http://dx.doi.org/10.17026/dans-z8d-wpah

Pienaar, L.V., \& K.J. Turnbull, 1973. The Chapman-Richards generalization of von Bertallanffy's growth model for basal area growth and yield in even-aged stands. Forest Science 19: 2-22. 
Schumacher, F.X. \& Hall, F.S., 1933. Logarithmic expression of timber-tree volume. Journal of Agricultural Research, v.47, n.9, p.719-734. 


\section{Bijlage 1. Opbrengsttabellen voor Amerikaanse eik Nederland 2018}

\section{Toelichting opbrengsttabellen}

In de kop van de opbrengsttabellen zijn een aantal standaard symbolen (IUFRO, 1959). In onderstaande tabel wordt de SI-eenheid vermeld en de betekenis van het symbool weergegeven.

\begin{tabular}{|c|c|c|}
\hline symbool & eenheid & betekenis \\
\hline Boniteit & & relatieve indeling in groeiklassen \\
\hline$h_{70}$ & $\mathrm{~m}$ & Site index (opperhoogte op 70 jr) \\
\hline$P 70$ & $m^{3} h a^{-1} j^{-1}$ & Productieklasse op $70 \mathrm{jr}{ }^{1)}$ \\
\hline$t$ & j & leeftijd vanaf kieming \\
\hline$h_{\text {top }}$ & $\mathrm{m}$ & opperhoogte \\
\hline$N$ & $h a^{-1}$ & stamtal per ha \\
\hline$S \%$ & & Hart-Becking dunning-index \\
\hline G & $m^{2} h a^{-1}$ & grondvlak per ha \\
\hline$d_{g}$ & $\mathrm{~cm}$ & diameter $(1,30 \mathrm{~m})$ van de middenboom ${ }^{2)}$ \\
\hline$h_{g}$ & $\mathrm{~m}$ & hoogte van de middenboom \\
\hline$V$ & $m^{3} h a^{-1}$ & volume per ha ${ }^{3)}$ \\
\hline$I c_{G}$ & $m^{2} h a^{-1} j^{-1}$ & lopende grondvlakbijgroei per ha per jaar op leeftijd $t$ jaar \\
\hline$I c_{V}$ & $m^{2} h a^{-1} j^{-1}$ & lopende volumebijgroei per ha per jaar op leeftijd $t$ jaar \\
\hline $\operatorname{Im} m_{G}$ & $m^{3} h a^{-1} j^{-1}$ & gemiddelde grondvlakbijgroei per ha per jaar tot op leeftijd $t$ jaar \\
\hline $\operatorname{Im}_{V}$ & $m^{3} h a^{-1} j^{-1}$ & gemiddelde volumebijgroei per ha per jaar tot op leeftijd $t$ jaar \\
\hline
\end{tabular}

1) gemiddelde productie, inclusief dunning maar exclusief sterfte (volumebijgroei) per ha tot op leeftijd 70 jaar

2) boom met gemiddeld boomgrondvlak en boomvolume

3) Het volume is gedefinieerd als het spilhoutvolume met schors. 


\section{Explanation yield tables}

In the header of the yield tables a number of standard symbols (IUFRO, 1959) are used. In the table below the SI units and the meaning of the symbols are given.

\begin{tabular}{|l|l|l|}
\hline symbol & unit & meaning \\
\hline Site class & & relative partition in site classes \\
$h_{70}$ & $\mathrm{~m}$ & Site index (top height at $70 \mathrm{yr})$ \\
$P 70$ & $\mathrm{~m}^{3} \mathrm{ha}^{-1} \mathrm{yr}^{-1}$ & Production class at $70 \mathrm{yr}$ 1) \\
$t$ & $\mathrm{j}$ & age since germination \\
$h_{\text {top }}$ & $\mathrm{m}$ & top height \\
$N$ & $\mathrm{ha}^{-1}$ & Number of stems per ha \\
$S \%$ & $\mathrm{~m}^{2} \mathrm{ha}^{-1}$ & S\% (Hart-Becking spacing index) \\
$G$ & $\mathrm{~cm}$ & Basal area per ha \\
$d_{g}$ & $\mathrm{~m}^{3}$ & diameter (1,30 $\mathrm{m}$ ) of the basal area mean tree \\
$h_{g}$ & $\mathrm{~m}^{3} \mathrm{ha}^{-1}$ & height of the basal area mean tree \\
$V$ & $\mathrm{~m}^{2} \mathrm{ha}^{-1} \mathrm{yr}^{-1}$ & volume per ha 2$)$ \\
$I c_{G}$ & $\mathrm{~m}^{2} \mathrm{ha}^{-1} \mathrm{yr}^{-1}$ & current basal area increment per ha per year at age $t$ \\
$I c_{V}$ & $\mathrm{~m}^{3} \mathrm{ha}^{-1} \mathrm{yr}^{-1}$ & current volume increment per ha per year at age $t$ \\
$I m_{G}$ & $\mathrm{~m}^{3} \mathrm{ha}^{-1} \mathrm{yr}^{-1}$ & mean vosal area increment per ha per year until age $t$ \\
$I m_{V}$ & meancrement per ha per year until age $t$ \\
\hline
\end{tabular}

1) Mean production, including thinning but excluding mortality (volume increment) per ha until age $70 \mathrm{yr}$.

2) The volume is defined as the stem volume over bark. 












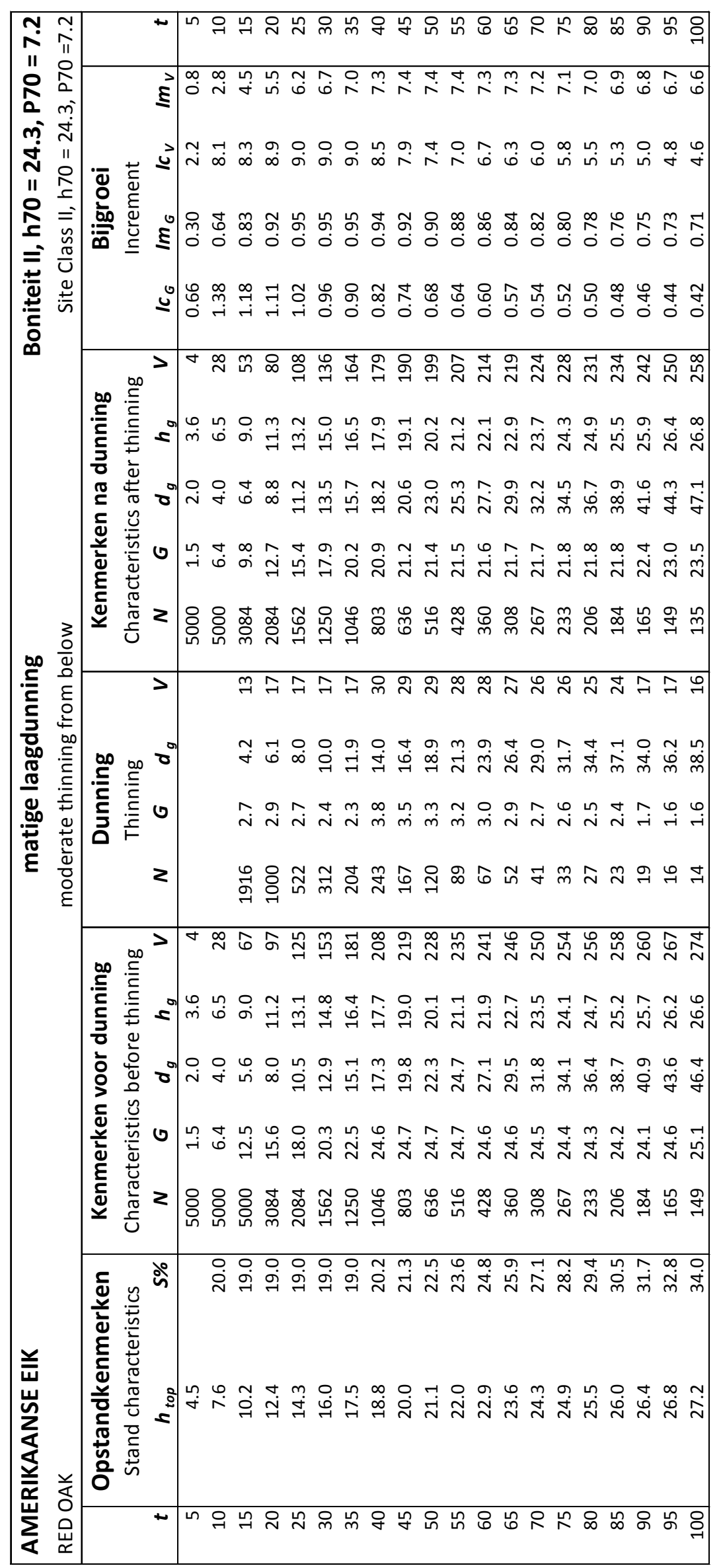




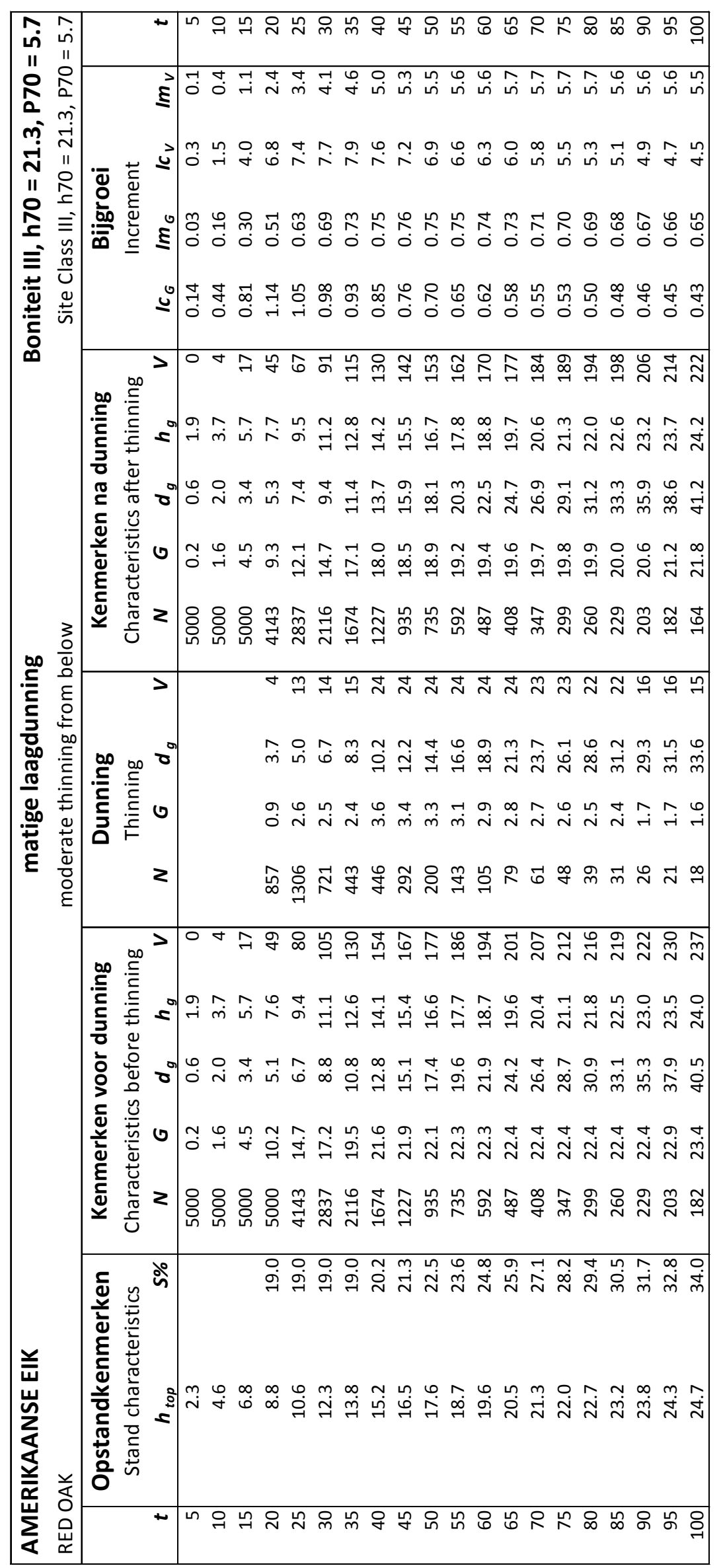




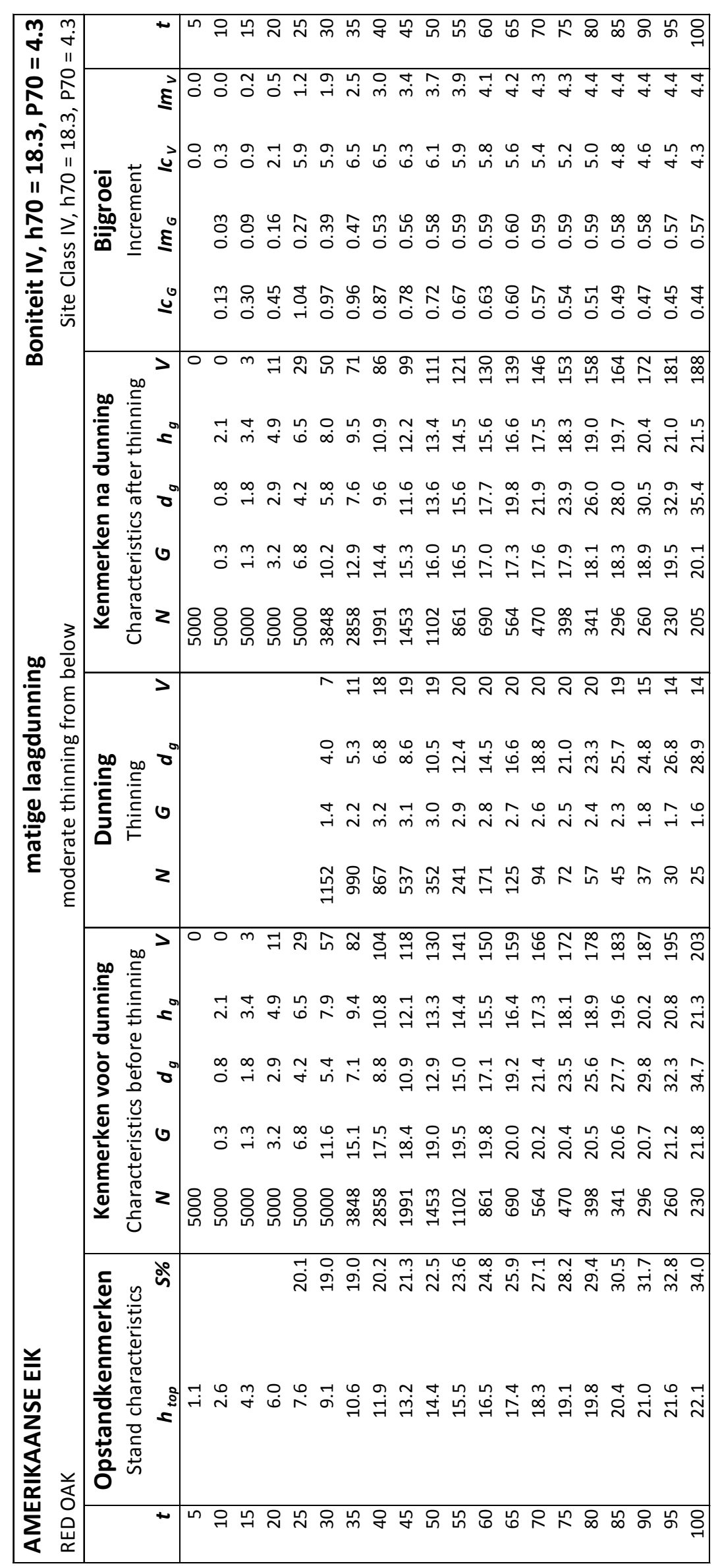




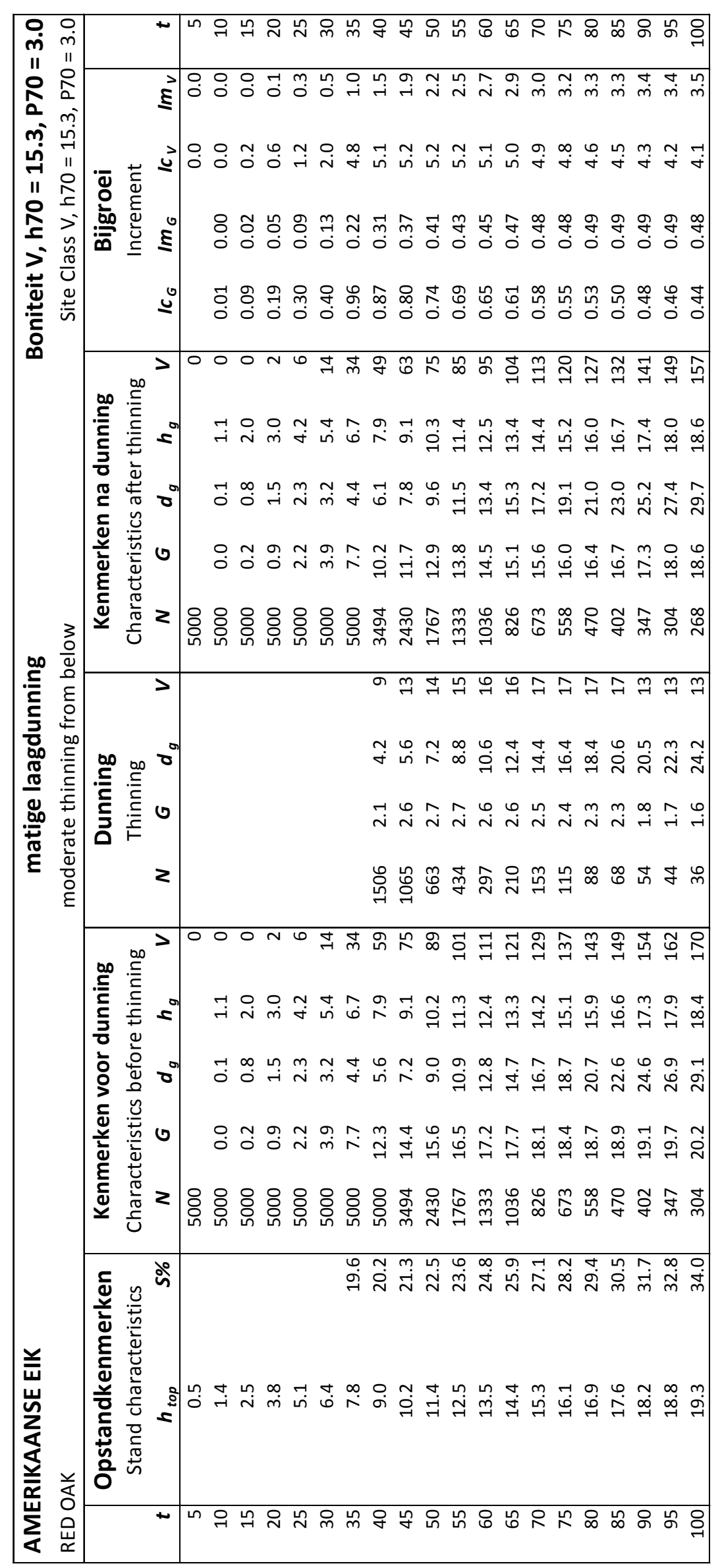

